\title{
The self-peptide repertoire plays a critical role in transplant tolerance induction
}

\author{
Eric T. Son, ${ }^{1}$ Pouya Faridi, ${ }^{2}$ Moumita Paul-Heng, ${ }^{1}$ Mario L. Leong, ${ }^{1}$ Kieran English, ${ }^{3}$ Sri H. Ramarathinam, ${ }^{2}$ Asolina Braun, ${ }^{2}$ \\ Nadine L. Dudek, ${ }^{2}$ Ian E. Alexander, ${ }^{4,5}$ Leszek Lisowski, ${ }^{6,7,8}$ Patrick Bertolino, ${ }^{3}$ David G. Bowen, ${ }^{1,3}$ Anthony W. Purcell, ${ }^{2}$ \\ Nicole A. Mifsud, ${ }^{2}$ and Alexandra F. Sharland ${ }^{1}$
}

\begin{abstract}
${ }^{1}$ Transplantation Immunobiology Group, University of Sydney Central Clinical School, Charles Perkins Centre, Faculty of Medicine and Health, Sydney, New South Wales, Australia. 2 Infection and Immunity Program, Department of Biochemistry and Molecular Biology, Biomedicine Discovery Institute, Monash University, Clayton, Victoria, Australia. ${ }^{3}$ Liver Immunology Group and AW Morrow Gastroenterology and Liver Centre, The University of Sydney and Royal Prince Alfred Hospital, Sydney, New South Wales, Australia. ${ }^{4}$ Cene Therapy Research Unit, Children's Medical Research Institute, The University of Sydney, Faculty of Medicine and Health and Sydney Children's Hospitals Network, Westmead, New South Wales, Australia. ${ }^{5}$ The University of Sydney, Sydney Medical School, Discipline of Child and Adolescent Health, Westmead, New South Wales, Australia. ${ }^{6}$ Translational Vectorology Research Unit, Children's Medical Research Institute, Faculty of Medicine and Health, The University of Sydney, Westmead, Australia. ${ }^{7}$ Vector and Genome Engineering Facility, Children's Medical Research Institute, Faculty of Medicine and Health, The University of Sydney, Westmead, Australia. ${ }^{8}$ Military Institute of Medicine, Laboratory of Molecular Oncology and Innovative Therapies, Warsaw, Poland.
\end{abstract}

While direct allorecognition underpins both solid organ allograft rejection and tolerance induction, the specific molecular targets of most directly alloreactive CD8 ${ }^{+} \mathrm{T}$ cells have not been defined. In this study, we used a combination of genetically engineered major histocompatibility complex class I (MHC I) constructs, mice with a hepatocyte-specific mutation in the class I antigen-presentation pathway, and immunopeptidomic analysis to provide definitive evidence for the contribution of the peptide cargo of allogeneic MHC I molecules to transplant tolerance induction. We established a systematic approach for the discovery of directly recognized pMHC epitopes and identified 17 strongly immunogenic $\mathrm{H}-2 \mathrm{~K}^{\mathrm{b}}$-associated peptides recognized by $\mathrm{CD}^{+} \mathrm{T}$ cells from B10.BR $\left(\mathrm{H}-2^{\mathrm{k}}\right)$ mice, 13 of which were also recognized by BALB/c $\left(\mathrm{H}-2^{\mathrm{d}}\right)$ mice. As few as 5 different tetramers used together were able to identify a high proportion of alloreactive $T$ cells within a polyclonal population, suggesting that there are immunodominant allogeneic MHC-peptide complexes that can account for a large component of the alloresponse.

\section{Introduction}

Allorecognition may result in either graft rejection, graft versus host disease, or transplantation tolerance, depending on the context in which the recipient immune system encounters the allogeneic major histocompatibility complex (MHC). When donor MHC class I (MHC I) molecules are expressed in the hepatocytes of recipient mice, subsequent skin or pancreatic islet grafts bearing the same donor allomorph are accepted indefinitely (1-3). Insights from this model can inform our understanding of allorecognition and transplant tolerance induction more broadly. MHC I molecules are ubiquitously expressed, and display a range of endogenous peptides (the class I immunopeptidome) reflecting protein turnover and normal cellular processes (4). While tolerance induction depends upon recognition of intact donor MHC I molecules

\section{Related Commentary: https://doi.org/10.1172/JCl154096}

Authorship note: PF and MPH contributed equally to this work.

Conflict of interest: ETS, MPH, AFS, NAM, AWP, PF, and NLD are named as coinventors in a patent application filed by the University of Sydney and Monash University (“Compositions for detecting alloreactive T cells," PCT/AU2020/051221).

Copyright: @ 2021, Son et al. This work is licensed under the Creative Commons Attribution 4.0 International License. To view a copy of this license, visit http://creativecommons.org/licenses/by/4.0/

Submitted: December 9, 2020; Accepted: August 18, 2021; Published: November 1, 2021. Reference information: J Clin Invest. 2021;131(21):e146771.

https://doi.org/10.1172/JCl146771. by recipient $\mathrm{CD}^{+} \mathrm{T}$ cells (3), the contribution of the self-peptide cargo of these molecules to tolerance induction in this setting is unknown. Many alloreactive T cell clones recognize epitopes comprising allogeneic MHC I molecules complexed with self-peptides (5-12). Conversely, peptide-independent direct allorecognition is also described $(7,13,14)$, and the ability of peptide-independent cytotoxic T lymphocyte (CTL) clones to bring about rapid destruction of allogeneic skin grafts has been demonstrated (15). At the level of a polyclonal alloresponse in vivo, there is limited information about the role of the donor's tissue-specific class I immunopeptidome in allorecognition and consequent immune responses that impact on graft survival.

Here, we examined the role of the liver immunopeptidome in transplantation tolerance induction using 2 different approaches. First, we engineered liver-specific adeno-associated viral (AAV) vectors encoding $\mathrm{H}-2 \mathrm{~K}^{\mathrm{b}}$ or $\mathrm{H}-2 \mathrm{~K}^{\mathrm{d}}$ as a single chain trimer (SCT) comprising the polymorphic heavy chain (HC), $\beta 2$ microglobulin $(\beta 2 \mathrm{~m})$ light chain, and a defined covalently bound peptide species $(16,17)$, thus excluding presentation of endogenous peptides by the allogeneic MHC I when these constructs were expressed in recipient hepatocytes (Figure 1A). In parallel, we introduced a global shift in the repertoire of peptides bound to allogeneic $\mathrm{H}-2 \mathrm{~K}^{\mathrm{d}}$. To accomplish this, we generated recipient mice in which the transporter associated with antigen processing (TAP1) protein was deficient only in hepatocytes (Tap1KOHep, $\mathrm{H}-2^{\mathrm{b}}$ ), and designed a construct expressing the $\mathrm{H}-2 \mathrm{~K}^{\mathrm{d}} \mathrm{HC}$ with a modification 
(YCAC) which stabilizes the molecule and permits occupancy by lower affinity peptides (18). Induction of tolerance to subsequent donor skin grafts was blocked by these manipulations, establishing that the endogenous peptide repertoire of hepatocytes makes an essential contribution to transplant tolerance induction.

Differential responses by alloreactive T cells to MHC I allomorphs expressed by various target tissues is cited as support for peptide-specific allorecognition $(6,19,20)$. Given that expression of allogeneic donor MHC I HC in recipient hepatocytes attenuates responses against both donor skin grafts and splenocyte stimulators $(1,3)$, we hypothesized that peptides critical for tolerance induction would be found within a subset shared by these tissues. We identified these peptides and assessed their recognition by activated alloreactive B10.BR T cells. Of 100 peptides selected for screening, 17 were bound by more than $5 \%$ of this $\mathrm{T}$ cell population, and 13 of these peptide-MHC (pMHC) epitopes were also recognized by $\mathrm{BALB} / \mathrm{c}$ mice. As few as 5 different pMHC tetramers used together were able to identify around $40 \%$ of alloreactive $\mathrm{T}$ cells within a polyclonal population, suggesting that there are immunodominant allogeneic MHC-peptide complexes that can account for a large proportion of the alloresponse. Accordingly, this panel enabled quantitation and phenotyping of alloreactive T cells in a model of secondary skin graft tolerance or rejection. The findings of this study represent a significant advance in our understanding of the role of endogenous peptides in direct $\mathrm{T}$ cell alloreactivity, and a springboard for further knowledge gain and technological development.

\section{Results}

Single-chain trimer constructs exclude presentation of endogenous peptides. In preceding studies $(1,3)$, we used AAV vectors encoding the donor MHC I HC. Within transduced hepatocytes, allogeneic $\mathrm{HC}$ associates with native $\beta 2 \mathrm{~m}$ and the resulting heterodimers are loaded with a repertoire of endogenous peptides (Figure 1A). To express allogeneic MHC I at high levels on recipient hepatocytes while excluding the presentation of naturally processed peptides, we engineered SCT constructs, each encoding the $\mathrm{HC}$ of $\mathrm{H}-2 \mathrm{~K}^{\mathrm{b}}, \beta 2 \mathrm{~m}$, and a single, defined $\mathrm{H}-2 \mathrm{~K}^{\mathrm{b}}$-restricted peptide (SIINFEKL [SIIN] or KIITYRNL [KIIT], Figure 1A), and packaged them in hepatocyte-specific AAV2/8 vectors. Sequences are shown in Supplemental Figure 1; supplemental material available online with this article; https://oi.org/10.1172/ JCI146771DS1. Transgene expression in hepatocytes was close to maximal by $\mathrm{d} 7$ following i.v. inoculation, and persisted through to at least d100, no significant increases in serum aspartate aminotransferase (AST) or alanine aminotransferase (ALT) levels were observed, and minimal cellular infiltration was detected by histology (Supplemental Figure 2). SCT molecules were expressed on transduced hepatocytes at equivalent levels to the heterotrimer formed by transgenic $\mathrm{H}-2 \mathrm{~K}^{\mathrm{b}} \mathrm{HC}$ with native $\beta 2 \mathrm{~m}$ and peptide (Figure 1B). To demonstrate exclusion of naturally processed peptides, we cotransduced B10.BR $\left(\mathrm{H}-2^{\mathrm{k}}\right)$ hepatocytes with AAV vectors encoding full-length chicken ovalbumin (OVA) and either HC-K $\mathrm{K}^{\mathrm{b}}$ or SCT-K $\mathrm{K}^{\mathrm{b}}$-KIIT, and stained them with a monoclonal antibody, 25D-1.16, which is specific for the OVA peptide SIINFEKL complexed with $\mathrm{K}^{\mathrm{b}}$. $\mathrm{K}^{\mathrm{b}}$-SIINFEKL was only detected at the surface of cells cotransduced with $\mathrm{HC}-\mathrm{K}^{\mathrm{b}}$ and not those expressing SCT-K $\mathrm{K}^{\mathrm{b}}$-KIIT (Figure 1, C and D). We extended this analysis to the broader endogenous peptide repertoire of $\mathrm{K}^{\mathrm{b}}$-transduced hepatocytes using immunoaffinity purification with the $\mathrm{H}-2 \mathrm{~K}^{\mathrm{b}}$-specific antibody $\mathrm{K} 9-178$, followed by reverse phase high-performance liquid chromatography (RP-HPLC) to collect peptide-containing fractions that were then analyzed using liquid chromatography with tandem mass spectrometry (LC-MS/MS) to identify bound peptides (Figure $2 \mathrm{~A}$ ). The $\mathrm{K}^{\mathrm{b}}$ binding motif of peptides eluted from $\mathrm{HC}-\mathrm{K}^{\mathrm{b}}$-transduced hepatocytes mirrored that obtained from $\mathrm{C} 57 \mathrm{BL} / 6\left(\mathrm{H}-2^{\mathrm{b}}\right)$ hepatocytes (Figure $2 \mathrm{~B}$ ). While there was greater diversity among the unique peptides isolated from $\mathrm{HC}-\mathrm{K}^{\mathrm{b}}$-transduced hepatocytes (Figure $2 \mathrm{C}$ ), there was substantial overlap between the peptide repertoires, with greater than $90 \%$ of the peptides from C57BL/6 hepatocytes also

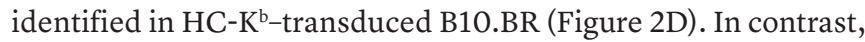
almost no $\mathrm{K}^{\mathrm{b}}$-bound peptides could be identified in association with SCT-K ${ }^{\mathrm{b}}$-KIIT, confirming exclusion of the endogenous peptide repertoire from presentation by this molecule (Figure 2C). Hepatocytes transduced with SCT-K ${ }^{\mathrm{b}}$-KIIT did not manifest any generalized defect in antigen processing, with both the numbers and repertoire of peptides isolated from the native allomorph $\mathrm{H}-2 \mathrm{~K}^{\mathrm{k}}$ being similar across all groups (Figure 2, $\mathrm{E}$ and $\mathrm{F}$ ). The full peptide data set can be found in Supplemental Table 1.

$S C T-K b-K I I T$ induces tolerance in alloreactive $T$ cells expressing the cognate $T$ cell receptor but not in a polyclonal alloreactive population. We first verified that SCT molecules were recognized by cells bearing their cognate TCRs in a manner analogous to the native epitope. Pulsing RMA-S cells with synthetic peptides KIITYRNL, SIINFEKL, and AAAAFAAL (minimum binding requirement for $\mathrm{H}-2 \mathrm{~K}^{\mathrm{b}}$ ) stabilized $\mathrm{K}^{\mathrm{b}}$ expression on the cell surface (Supplemental Figure 3, A and B). Similar levels of surface expression were achieved by transient transfection of RMA-S cells with the corresponding SCT constructs (Supplemental Figure 3C). Using interferon-gamma (IFN- $\gamma$ ) ELISPOT, we found a strong, specific response to SCT-K ${ }^{\mathrm{b}}$-KIIT by Des-RAG TCR-transgenic T cells which express the cognate TCR. SCT-K $\mathrm{K}^{\mathrm{b}}$-SIIN was similarly recognized by OT-I-RAG T cells (Supplemental Figure 3D). Following adoptive transfer into B10.BR mice transduced with SCT-K ${ }^{\mathrm{b}}$-KIIT, Des-RAG T cells proliferated vigorously, expanding more than those transferred to the positive control $178.3\left(\mathrm{H}-2^{\mathrm{k}}+\right.$ $\left.\mathrm{K}^{\mathrm{b}}\right)$ mice after 2 days $(P<0.0001$, Supplemental Figure 3, E and $\mathrm{F})$. The polyclonal responder population of liver leukocytes from $\mathrm{B} 10 . \mathrm{BR}$ mice also contained $\mathrm{CD} 8^{+} \mathrm{T}$ cells, which were activated in response to transduction with $\mathrm{SCT}-\mathrm{K}^{\mathrm{b}}-\mathrm{KIIT}$. Naive or primed B10. BR mice were inoculated with SCT-K ${ }^{\mathrm{b}}$-KIIT, and liver leukocytes isolated 7 days later (Supplemental Figure 4A). Activated CD8 ${ }^{+}$ $\mathrm{T}$ cells, defined as CD $44^{+} \mathrm{PD}-1^{\mathrm{hi}}$, increased upon priming or transduction with SCT-K $\mathrm{K}^{\mathrm{b}}$-KIIT, with a further augmentation when primed mice received SCT-K $\mathrm{K}^{\mathrm{b}}$-KIIT vector (Supplemental Figure $4 \mathrm{~B})$. Activated $\mathrm{CD}^{+} \mathrm{T}$ cells from transduced mice recognized $\mathrm{K}^{\mathrm{b}}$-KIIT dextramers but not dextramers of the self-pMHC complex $\mathrm{K}^{\mathrm{k}}$-EEEPVKKI, while PD-1 $1^{-}$bystander $\mathrm{CD} 8^{+} \mathrm{T}$ cells did not bind either dextramer (Supplemental Figure 4, C and D).

Next, we determined that Des-RAG T cells alone were capable of rejecting $\mathrm{K}^{\mathrm{b}}$-bearing 178.3 skin grafts upon adoptive transfer to B10.BR-RAG recipients (Figure 3, A and B). Graft survival was inversely related to the $T$ cell dose; 50,000 transferred cells yielded a median graft survival comparable to that in B10.BR 

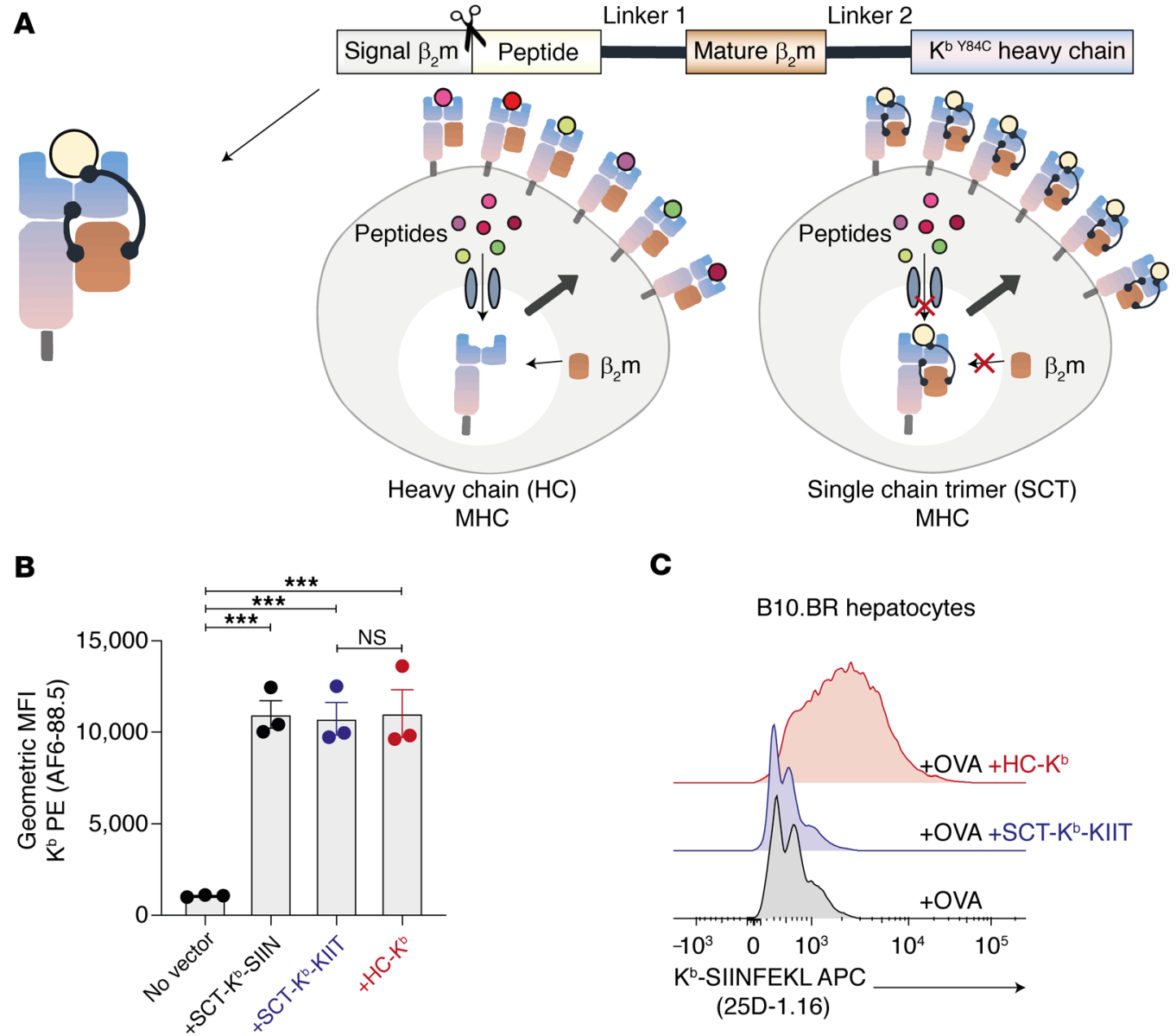

C

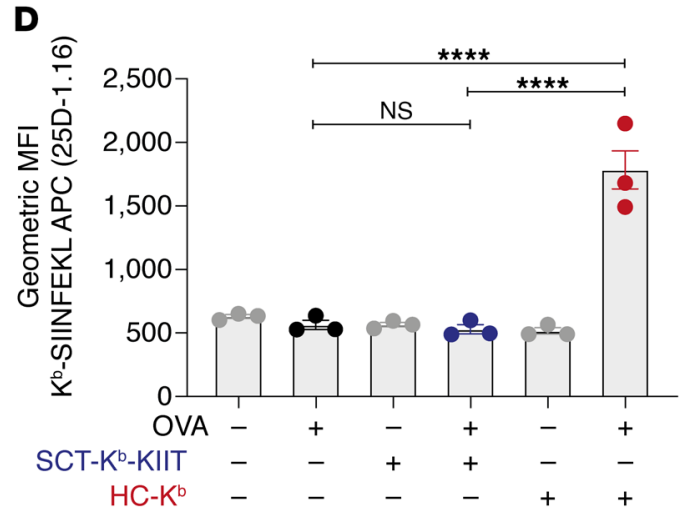

Figure 1. SCT constructs express a single pMHC epitope at the cell surface. (A) Schematic diagram of SCT pMHC constructs. MHC I HC expressed in hepatocytes can bind endogenous peptides and associate with native $\beta 2 \mathrm{~m}$ to form a wide repertoire of pMHC complexes. Conversely, SCT constructs exclude binding of endogenous peptides and present a single type of pMHC epitope on the cell surface. (B-D) B10.BR mice were transduced with AAVSCT-K ${ }^{b}-S I I N$, AAV-SCT-K $K^{b}-K I I T$, or AAV-HC-K ${ }^{b}$ with or without AAV-OVA. Flow cytometric analysis of isolated hepatocytes (d7) is shown. (B) Equivalent levels of $\mathrm{H}-2 \mathrm{~K}^{\mathrm{b}}$ cell surface expression were demonstrated using the mAb AF6-88.5. (C and $\mathbf{D}$ ) Presentation of SIINFEKL (OVA $\left.257-264\right)$ peptide bound to $\mathrm{H}-2 \mathrm{~K}^{\mathrm{b}}$ was detected using an anti- $K^{b}-S I I N F E K L$ mAb (25D-1.16). Cotransduction with AAV-OVA permitted presentation of SIINFEKL by hepatocytes transduced with AAV-HC-K . Conversely, the SCT-Kb-KIIT construct excluded presentation of endogenously processed SIINFEKL peptide. For $\mathbf{B}$ and $\mathbf{D}, n=3$ biological replicates per group, mean \pm SEM are shown. Statistical analysis comprised 1-way ANOVA with Sidak's multiple comparison test: ${ }^{* * *} P<0.001,{ }^{* * *} P<$ 0.0001. Panel C depicts one representative experiment (from $n=3$ ).

mice with a polyclonal $\mathrm{K}^{\mathrm{b}}$-reactive $\mathrm{T}$ cell repertoire and this dose was used in subsequent experiments. All grafts to reconstituted B10.BR-RAG mice treated with SCT-K $\mathrm{K}^{\mathrm{b}}$-KIIT survived indefinitely, whereas no graft survival prolongation was observed in reconstituted mice receiving the control vector SCT-K ${ }^{\mathrm{b}}$-SIIN (Figure
3C). Surviving grafts appeared normal macroscopically (Figure 3D) and upon histology (Figure 3E), with continued expression of $\mathrm{H}-2 \mathrm{~K}^{\mathrm{b}}$. In contrast, transduction of wild-type B10.BR mice with either SCT-K ${ }^{b}-K I I T$ or SCT-K $\mathrm{K}^{\mathrm{b}}$-SIIN only briefly delayed graft rejection (Figure $3 \mathrm{~F}$ ). 
A

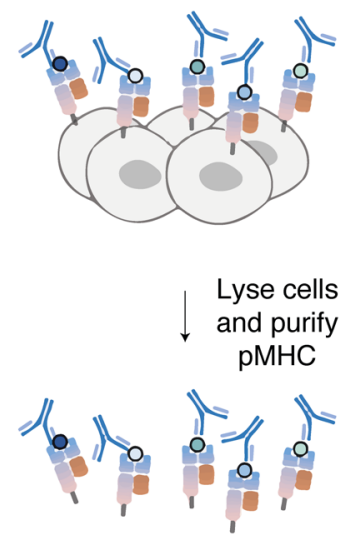

Acetic acid RP-HPLC

$$
0_{0}^{0} 0
$$

LC-MS/MS

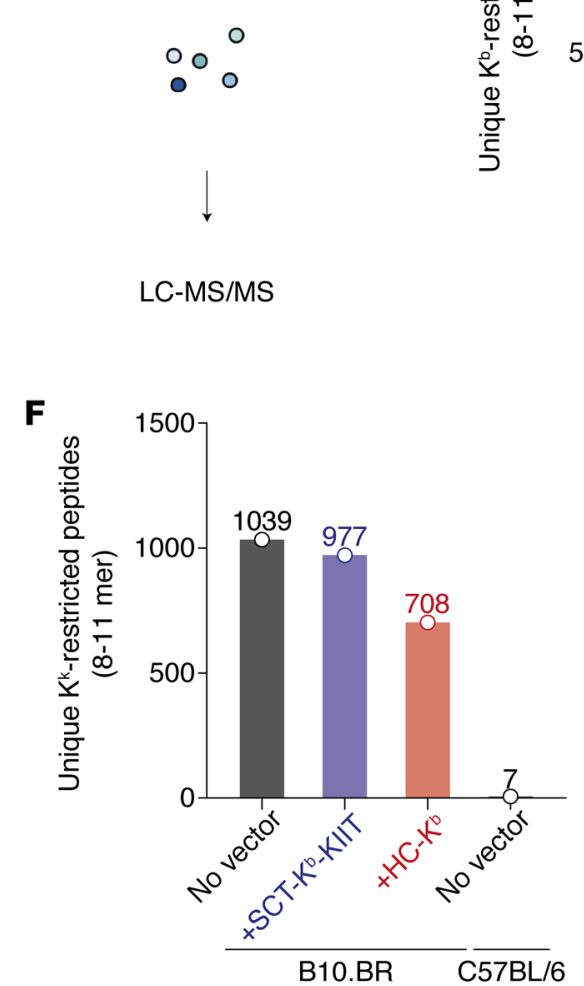

B

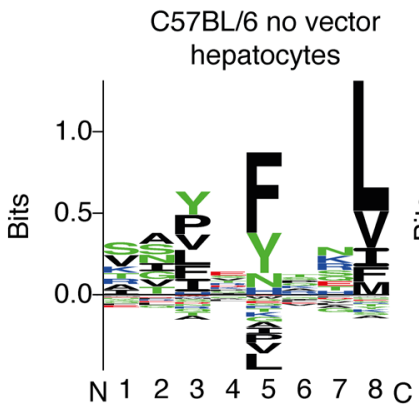

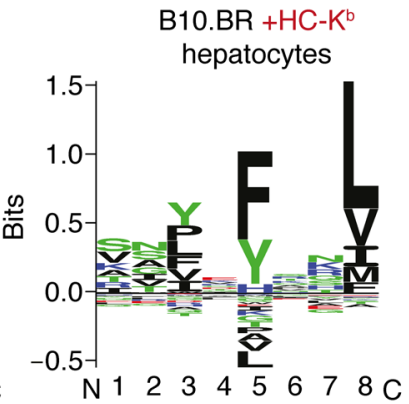

$\mathrm{B} 10 . \mathrm{BR}+\mathrm{HC}-\mathrm{K}^{\mathrm{b}}$

hepatocytes

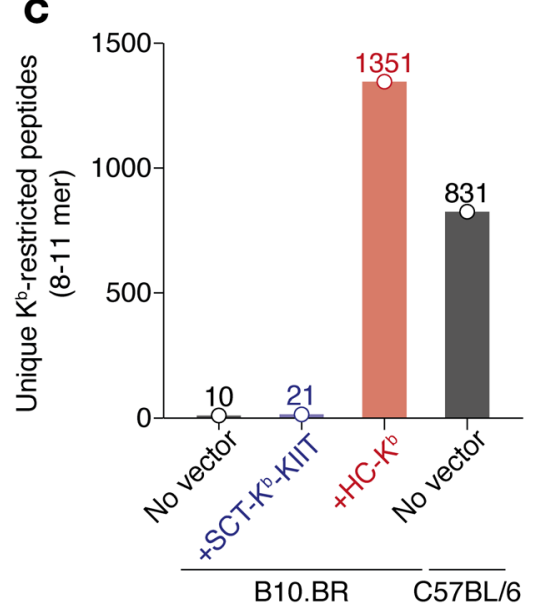

D

Unique $\mathrm{K}^{\mathrm{b}}$-restricted peptides

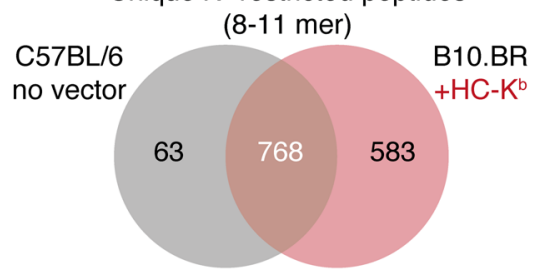

E

Unique $\mathrm{K}^{\mathrm{k}}$-restricted peptides

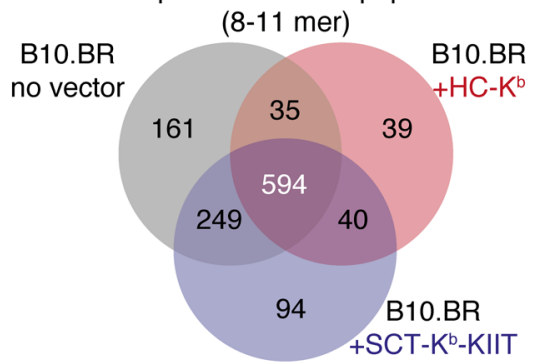

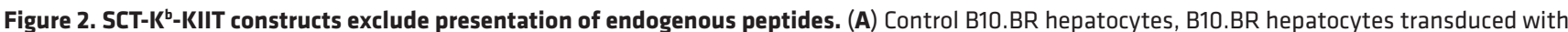
either AAV-HC- $\mathrm{K}^{\mathrm{b}}$ or AAV-SCT- $\mathrm{K}^{\mathrm{b}}-\mathrm{K} I I T$, or control $\mathrm{C} 5 \mathrm{~B} \mathrm{~B} / 6$ hepatocytes underwent immunoaffinity purification in order to identify unique $\mathrm{H}-2 \mathrm{~K}^{\mathrm{b}}$ and $\mathrm{H}-2 \mathrm{~K}^{\mathrm{k}}$ peptides. A FDR of $5 \%$ was employed. Two replicate experiments were performed. Samples from 4 mice were pooled/group for each replicate, and combined lists of peptides present in either or both replicates were generated. (B) $\mathrm{H}-2 \mathrm{~K}^{\mathrm{b}}$-binding motifs were generated from a nonredundant list of 8- to 11-mer peptides using the GibbsCluster 2.0 algorithm. The binding motif obtained from B10.BR hepatocytes transduced with AAV-HC- $K^{b}$ closely reflected that from $\mathrm{C} 57 \mathrm{BL} / 6\left(\mathrm{H}-2^{\mathrm{b}}\right)$ hepatocytes. (C and D) Abundant $\mathrm{K}^{\mathrm{b}}$-binding peptides were isolated from both $\mathrm{C} 57 \mathrm{BL} / 6$ and AAV-HC- $\mathrm{K}^{\mathrm{b}}$-transduced B10.BR hepatocytes, with significant overlap between repertoires, while very few $\mathrm{K}^{\mathrm{b}}$-binding peptides could be eluted from B10.BR hepatocytes transduced with AAV-SCT-K ${ }^{\mathrm{b}}-\mathrm{KIIT}$. (E and F) Comparable numbers of $\mathrm{K}^{\mathrm{k}}$-binding peptides were isolated from all B10.BR hepatocyte samples, but not from C57BL/6 mice, which lack this allomorph. In $\mathbf{C}$ and $\mathbf{F}$, bars represent the cumulative number of unique peptides obtained from replicate experiments.

The YCAC mutation alters the repertoire of $H-2 K d$-bound peptides in both TAP1KOHep and C57BL/6 mice. Mice with a conditional deletion of Tap1 in hepatocytes (Tap1KOHep, $\mathrm{H}-2^{\mathrm{b}}$ ) express trace amounts of the native $\mathrm{MHC}$ I allomorphs $\mathrm{H}-2 \mathrm{~K}^{\mathrm{b}}$ and $\mathrm{H}-2 \mathrm{D}^{\mathrm{b}}$ at the hepatocyte surface (Figure 4, A-D). Importantly, expression of these molecules on most other cell types within the liver, in other tissues (such as spleen, thymus, and lymph node), and in Tap $1^{\mathrm{f} / \mathrm{fl}}$ control mice was normal (Figure 4, A-D and Supplemental Figure 5). Transduction of Tap1KOHep mice with a vector encoding the $\mathrm{H}-2 \mathrm{~K}^{\mathrm{d}} \mathrm{HC}\left(\mathrm{HC}-\mathrm{K}^{\mathrm{d}}\right)$ resulted in surface expression of $\mathrm{H}-2 \mathrm{~K}^{\mathrm{d}}$, which was clearly positive with respect to untransduced controls, yet was reduced in comparison to that in $\mathrm{C} 57 \mathrm{BL} / 6$ or $\operatorname{Tap}^{\mathrm{fl} / \mathrm{fl}}$ mice (Figure 
A

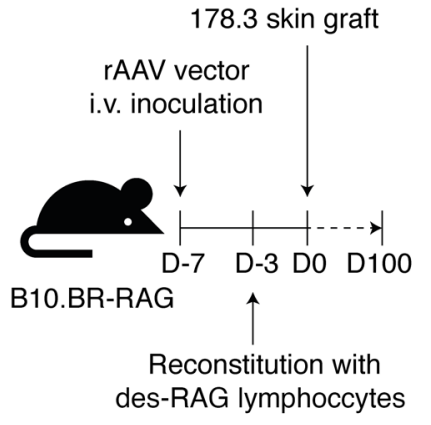

B

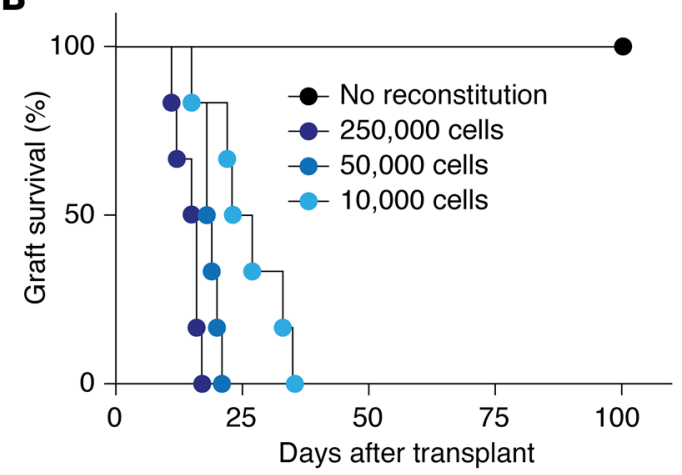

C

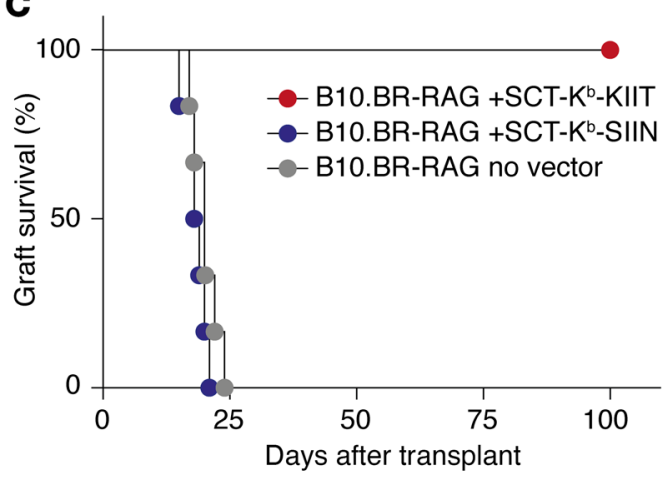

E

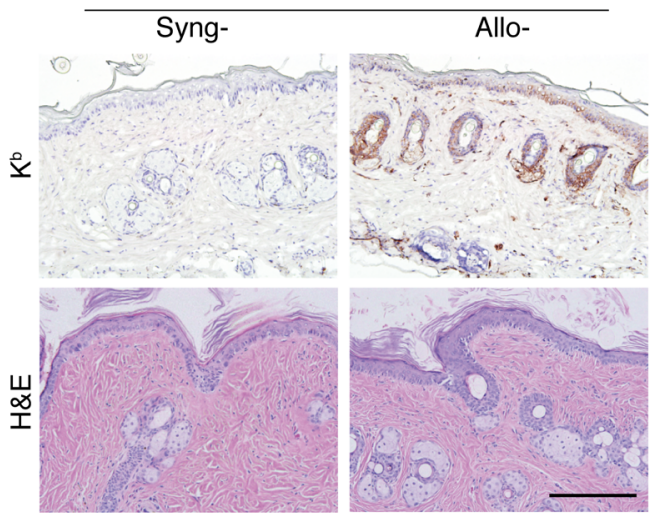

D

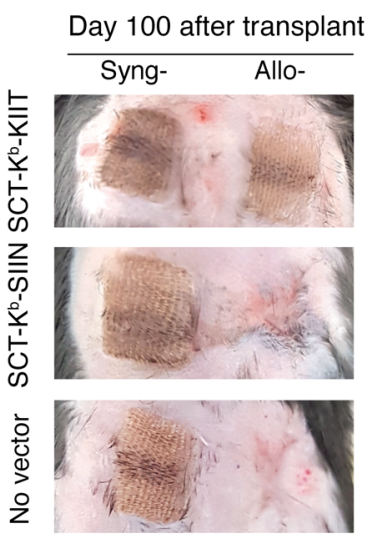

Figure 3. Expression of the SCT-K $\mathrm{K}^{\mathrm{b}}-\mathrm{KIIT}$ construct in recipient hepatocytes prevents skin graft rejection mediated by alloreactive CD8+ $\mathrm{T}$ cells expressing the cognate TCR but does not induce tolerance in a polyclonal alloreactive population. (A) B10.BR-RAG mice were reconstituted with $1.0 \times 10^{4}$ to $2.5 \times 10^{5}$ Des-RAG lymphocytes, 3 days prior to receiving a Kb-bearing 178.3 skin graft. Some mice were also inoculated with AAV vectors. (B) 178.3 skin grafts survived indefinitely on immunodeficient B10.BR-RAG hosts. Progressive shortening in survival accompanied adoptive transfer of increasing cell numbers (Mantel-Cox log-rank test for trend: $P<0.0001, n=6$ per group). A dose of 50,000 cells was used subsequently. (C) Inoculation of reconstituted B10.BR-RAG recipients with AAV-SCT-K ${ }^{\mathrm{b}}-\mathrm{KIIT}$ resulted in indefinite graft survival, whereas treatment with AAV-SCT-K ${ }^{\mathrm{b}}-\mathrm{SIIN}$ offered no survival prolongation compared with that in untransduced recipients; median survival time (MST) of 18.5 days versus 20 days $(P=0.2, P=0.0005$ between mice receiving AAV-SCT-K $K^{\mathrm{b}}-\mathrm{KIIT}$ or AAV-SCT-K ${ }^{\mathrm{b}}-\mathrm{SIIN}$, all groups $n=6$ ). (D) Representative macroscopic images (from $\left.n=6\right)$ demonstrate continued allograft survival in reconstituted B10.BR-RAG mice treated with AAV-SCT- $K^{\mathrm{b}}-\mathrm{KIIT}$ but not other groups at 100 days after transplantation. (E) Representative IHC and H\&E images showing syngeneic (B10.BR-RAC) and allogeneic (178.3) skin grafts 100 days posttransplant (scale bar: $100 \mu \mathrm{m}$ ). Skin transplants are morphologically normal, with persistent expression of $\mathrm{H}-2 \mathrm{~K}^{\mathrm{b}}$ in 178.3 grafts. (F) Immunosufficient B10.BR mice were inoculated with either AAV-HC-K ${ }^{\mathrm{b}}$, AAV-SCT-K $\mathrm{K}^{\mathrm{b}}$ KIIT, or AAV-SCT-K ${ }^{\mathrm{b}}$-SIIN ( $n=6$ per group) or were not transduced $(n=9)$. Seven days after inoculation, the mice received $178.3 \mathrm{skin}$ grafts. In these mice, expression of either SCT-K ${ }^{\mathrm{b}}-\mathrm{KIIT}$ or SCT-K ${ }^{\mathrm{b}}-\mathrm{SIIN}$ led to a modest increase in graft survival (MST of 25 days versus 17 days in no vector controls, $P=0.0007$ ). However, only expression of $\mathrm{H}-2 \mathrm{~K}^{\mathrm{b}}$ loaded with the endogenous peptide repertoire was able to induce tolerance to 178.3 skin grafts. $P=0.0005$ between B10.BR inoculated with AAV-HC-Kb and either AAV-SCT-K ${ }^{\mathrm{b}}-\mathrm{KIIT}$ or AAV-SCT-Kb-SIIN. (C and F) Mantel-Cox log-rank test. 
A Hepatocytes

Liver leukocytes

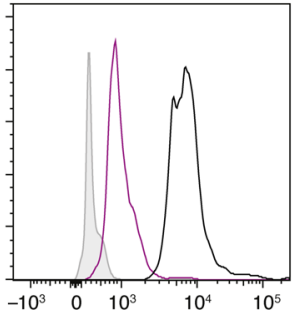

$K^{b} \mathrm{PE}$

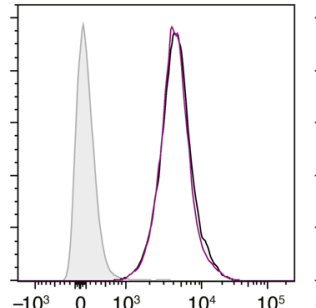

$\begin{array}{llll}-10^{3} & 0 & 10^{3}\end{array}$

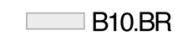

Tap ${ }^{|t| t \mid}$

C
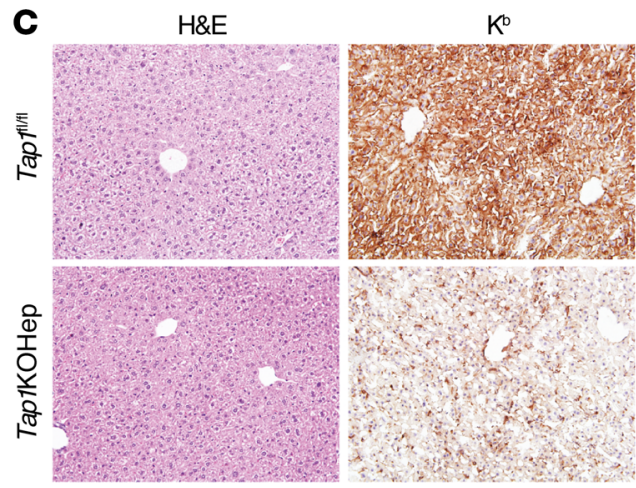

E $\quad$ C57Bᄂ 6

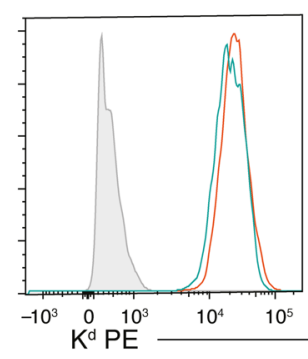

Taptil|r|

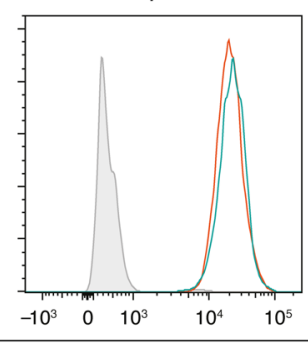

Splenocytes

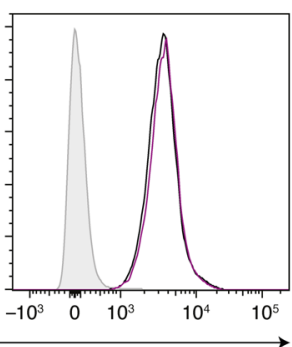

Tap1KOHep

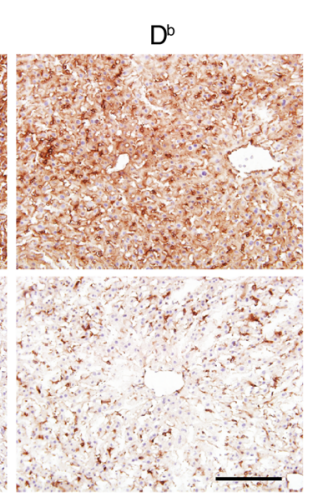

D
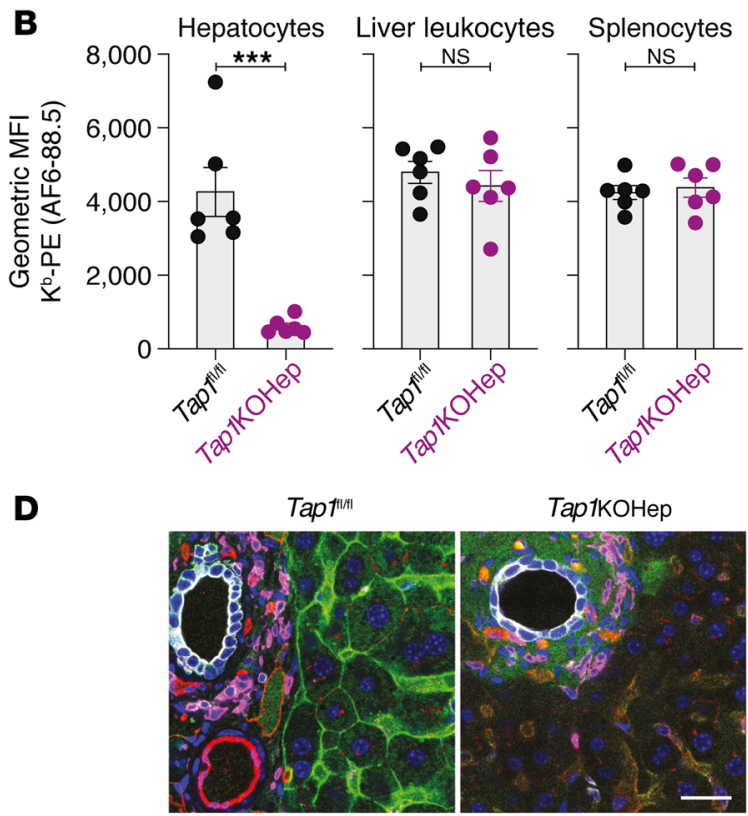

DAPI CD31 CK19 CD45 K

F
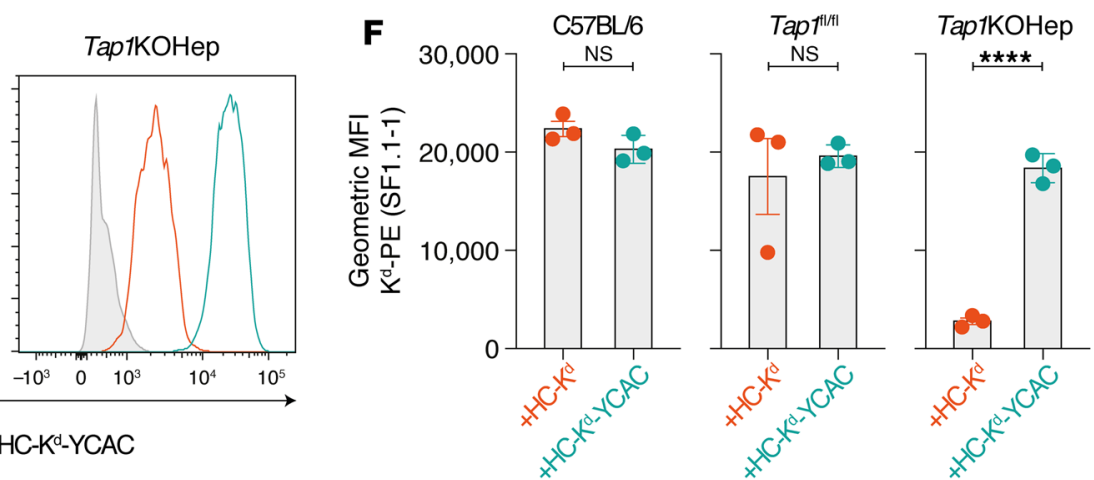

Tap1KOHep $+\mathrm{HC}-\mathrm{K}^{\mathrm{d}}-\mathrm{YCAC}$
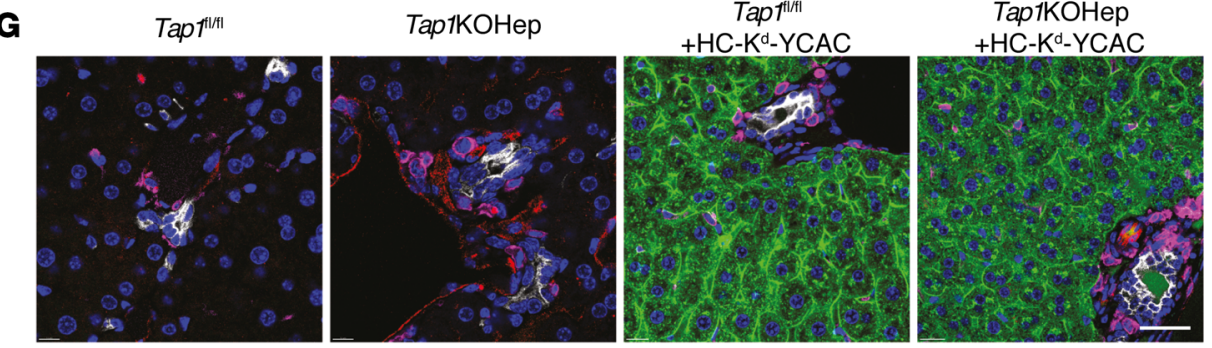

DAPI CD31 CK19 CD45 K

Figure 4. Hepatocytes from Tap1KO Hep mice express high levels of $\mathbf{H - 2} K^{\mathrm{d}}$ following transduction with AAV-HC-Kd-YCAC. (A-D) Expression of $\mathrm{K}^{\mathrm{b}}$ on liver leukocytes and splenocytes was equivalent between Tap1KOHep and Tap $7^{\mathrm{fl} / \mathrm{fl}}$ mice, while much lower levels were detected on hepatocytes from Tap1KOHep. Representative flow plots from $n=6$. (C) Tap1KOHep and Tap $7^{\text {fl/ffl }}$ livers are morphologically normal. IHC staining demonstrates expression of $K^{\mathrm{b}}$ and $\mathrm{D}^{\mathrm{b}}$ in nonparenchymal cells from Tap1KOHep livers, while $\mathrm{K}^{\mathrm{b}}$ and $\mathrm{D}^{\mathrm{b}}$ are absent from hepatocytes in these mice (representative images, $n=3$ ). (D) Thick sections $(150 \mu \mathrm{m})$ from Tap1KOHep or Tap $7^{\mathrm{fl} / \mathrm{fl}}$ livers were stained with antibodies against $\mathrm{H}-2 \mathrm{~K}^{\mathrm{b}}, \mathrm{CD} 31, \mathrm{CK} 19$, and CD45. Confocal micrographs were obtained. $\mathrm{K}^{\mathrm{b}}$ is ubiquitously expressed in Tap ${ }^{f / / f 1}$, but absent from hepatocytes in Tap1KOHep (representative images, $n=3$ ). (E and F) While $\mathrm{H}-2 \mathrm{~K}^{\mathrm{d}}$ was clearly present on hepatocytes from Tap1KOHep transduced with AAV-HC-Kd, expression did not reach that in TAP-sufficient mice transduced with the same vector. To achieve robust cell surface expression of $\mathrm{K}^{\mathrm{d}}$, we designed a construct where point mutations (Y84C and A139C; YCAC) stabilize expression of $K^{\mathrm{d}}$ when empty or loaded with low-affinity peptides. Inoculation of Tap1KOHep mice with AAV-HC-Kd-YCAC yielded comparable expression to that of TAP-sufficient

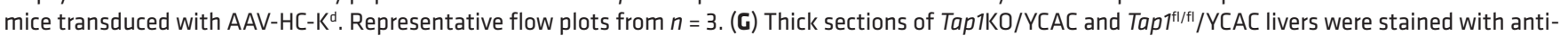
bodies against $\mathrm{H}-2 \mathrm{~K}^{\mathrm{d}}, \mathrm{CD} 31, \mathrm{CK} 19$, and CD45. Equivalent strong expression of $\mathrm{K}^{\mathrm{d}}$ in hepatocytes, but not other cell types, was observed for both treatment groups (representative of $n=3$ ). Scale bars: $100 \mu \mathrm{m}$ ( $\mathbf{C}$ and $\mathbf{E}), 40 \mu \mathrm{m}$ ( $\mathbf{D}$ and $\mathbf{G}$ ). In $\mathbf{B}$ and $\mathbf{F}$, mean \pm SEM are shown. Statistical analysis comprised unpaired Student's $t$ test: ${ }^{* *} P<0.001,{ }^{* * * *} P<0.0001$. 
4, E and F). Increasing the vector dose did not yield an appreciable increase in surface expression (data not shown), most likely because of instability of suboptimally loaded $\mathrm{H}-2 \mathrm{~K}^{\mathrm{b}}$ molecules and their rapid recycling from the cell surface (21-23). To counter this, we designed a construct where the point mutations Y84C and $\mathrm{A} 139 \mathrm{C}$ (YCAC) in the $\mathrm{H}-2 \mathrm{~K}^{\mathrm{d}} \mathrm{HC}$ result in the formation of a disulphide bridge, which stabilizes the molecule when empty or loaded with lower affinity peptides (18). This modification does not interfere with TCR recognition of the bound peptide (18). The construct sequence is shown in Supplemental Figure 1. Comparable strong expression of $\mathrm{H}-2 \mathrm{~K}^{\mathrm{d}}$ on the surface of hepatocytes was achieved in Tap1KOHep mice treated with $\mathrm{HC}-\mathrm{K}^{\mathrm{d}}-\mathrm{YCAC}$ and in $\operatorname{Tap}^{\mathrm{f} / \mathrm{fl}}$ mice receiving either the $\mathrm{HC}-\mathrm{K}^{\mathrm{d}}$ or $\mathrm{HC}-\mathrm{K}^{\mathrm{d}}-\mathrm{YCAC}$ vectors (Figure 4, E-G). Immunoaffinity purification and LC-MS/ MS were used to characterize the bound self-peptide repertoire of transduced hepatocytes. There were 9570 unique peptides identified from C57BL/6 hepatocytes transduced with $\mathrm{HC}-\mathrm{K}^{\mathrm{d}}$ (B6/HC), compared with 7690, 7776, and 6417 unique peptides respectively, from C57BL/6, Tap $1^{\mathrm{fl} / \mathrm{fl}}$, and Tap1KOHep transduced with HC-Kd-YCAC (i.e., B6/YCAC, Tap1 1/fll /YCAC, and Tap1KO/ YCAC). The full data set can be found in Supplemental Table 1, while distribution of peptide lengths and spectral intensities is shown in Supplemental Figure 6, along with the gene ontology analysis of the subcellular location and function of the source proteins. While the sequences of eluted 9-mer peptides from B6/ HC, B6/YCAC, and Tap1 ${ }^{\mathrm{I} / \mathrm{fl}} / \mathrm{YCAC}$ corresponded to the canonical motif for $\mathrm{H}-2 \mathrm{~K}^{\mathrm{d}}$, with a tyrosine $(\mathrm{Y})$ residue predominant at position 2, and leucine (L) or isoleucine (I) most frequently found at position 9, this motif was not observed for the peptides eluted from Tap1KO/YCAC (Figure 5, A and B). Compared with B6/ $\mathrm{HC}$, just under $45 \%$ of peptides were common to B6/YCAC or $\operatorname{Tap}^{\mathrm{f} / \mathrm{fl}} / \mathrm{YCAC}$, while $22 \%$ were shared with Tap1KOHep/YCAC (Figure 5C). Similarity across peptide repertoires was increased when the comparison was weighted for peptide abundance (Figure 5C). The peptide SYFPEITHI (SYFP) was common to all $\mathrm{K}^{\mathrm{d}}$ repertoires, and comparable proportions of $\mathrm{CD} 8^{+} \mathrm{T}$ cells recognizing $\mathrm{K}^{\mathrm{d}}$-SYFP could be detected among the liver leukocytes isolated from primed Tap1KO/YCAC as well as from primed B6/ YCAC and B6/HC (Figure 5D), consistent with published reports that the YCAC mutation alters the peptide repertoire but does not interfere with TCR recognition of presented peptides $(18,24)$.

Increasing perturbation of the hepatocyte $H-2 K d$ peptide repertoire correlates with progressive reduction of Kd-bearing skin graft survival in transduced mice. Mice were inoculated with AAV vectors encoding $\mathrm{HC}-\mathrm{K}^{\mathrm{d}}, \mathrm{HC}-\mathrm{K}^{\mathrm{d}}-\mathrm{YCAC}$, or SCT- $\mathrm{K}^{\mathrm{d}}$ with the peptide SYFPEITHI (SCT-K ${ }^{\mathrm{d}}$-SYFP), 7 days prior to transplantation with a B6.Kd skin graft (Figure 6A). The construct sequence and expression data for SCT-K ${ }^{\mathrm{d}}$-SYFP are shown in Supplemental Figures 1 and 7, respectively. The majority of C57BL/6 or Tap $1^{1 / 1 / 1}$ mice transduced with $\mathrm{HC}-\mathrm{K}^{\mathrm{d}}$ accepted $\mathrm{K}^{\mathrm{d}}$-bearing B6.Kd skin grafts indefinitely, whereas median survival of $\mathrm{B} 6 . \mathrm{Kd}$ skin grafts to $\mathrm{C} 57 \mathrm{BL} / 6$ or Tap ${ }^{\mathrm{t} / \mathrm{ll}}$ mice treated with $\mathrm{HC}-\mathrm{K}^{\mathrm{d}}-\mathrm{YCAC}$ was reduced to $62.5 \pm 5.3$ days and 52.5 \pm 9.2 days, respectively (Figure 6B). Graft survival in Tap1KOHep mice inoculated with $\mathrm{HC}-\mathrm{K}^{\mathrm{d}}-\mathrm{YCAC}$ was further reduced to $20 \pm$ 1.9 days, similar to that in $\mathrm{C} 57 \mathrm{BL} / 6$ mice which received a vector encoding SCT- $\mathrm{K}^{\mathrm{d}}$-SYFP $(17 \pm 1.2$ days). Median graft survival in no vector control mice was $12.5 \pm 0.6$ days for $\mathrm{C} 57 \mathrm{BL} / 6$ and $10 \pm 0.6$ days for Tap1KOHep $(P<0.0001$ for overall survival trend, Figure $6 \mathrm{~B})$. Failure to induce tolerance was not associated with loss of transgene expression in the transduced livers (Supplemental Figure 7). Instead, progressive loss of ability of $\mathrm{H}-2 \mathrm{~K}^{\mathrm{d}}$ gene transfer to prolong B6.Kd skin graft survival correlated with increasing disturbance of the hepatocyte $\mathrm{K}^{\mathrm{d}}$ peptide repertoire in the various experimental groups. These findings, along with the inability of SCT- $\mathrm{K}^{\mathrm{b}}$ vectors to induce tolerance in polyclonal alloreactive $\mathrm{T}$ cell populations, demonstrate the importance of the hepatocyte immunopeptidome in transplantation tolerance induction following donor MHC I gene transfer to the liver.

Profiling the tissue-specific immunopeptidomes of hepatocytes, skin, and spleen. Given the ability of $\mathrm{H}-2 \mathrm{~K}^{\mathrm{b}}$ or $\mathrm{K}^{\mathrm{d}} \mathrm{HC}$ expressed in recipient hepatocytes to induce tolerance to allogeneic skin grafts and to downmodulate responses against donor splenocyte stimulators $(1,3)$, we postulated that the peptides critical for allorecognition and tolerance induction would be found within a subset common to these 3 tissue types. The self-peptide repertoires of transduced hepatocytes, grafted donor skin, and donor spleen were determined using a combination of immunoaffinity purification and RP-HPLC to liberate and collect peptide-containing fractions from MHC I with LC-MS/MS for peptide identification, for both the 178.3 to $\mathrm{B} 10 . \mathrm{BR}$ ( $\mathrm{K}^{\mathrm{b}}$ mismatch, $\mathrm{H}-2^{\mathrm{k}}$ background) and B6.Kd to C57BL/6 ( $\mathrm{K}^{\mathrm{d}}$ mismatch, $\mathrm{H}-2^{\mathrm{b}}$ background) strain combinations, as outlined in Figure 7A. The lists of common peptides are found in Supplemental Table $2\left(\mathrm{H}-2 \mathrm{~K}^{\mathrm{d}}\right)$ and Supplemental Table 3 $\left(\mathrm{H}-2 \mathrm{~K}^{\mathrm{b}}\right)$. For $\mathrm{H}-2 \mathrm{~K}^{\mathrm{d}}, 880$ common peptides were identified across the 3 tissue types (Figure 7B), whereas there were 1083 common $\mathrm{K}^{\mathrm{b}}$-binding peptides (Figure $7 \mathrm{C}$ ). The peptide length distributions (Figure 7, D and F) and binding motifs (Figure 7, E and G) were as anticipated for the respective allomorphs and were similar across tissue types. Of note, the common peptide pool was more limited when TAP-sufficient, or particularly TAP-deficient, hepatocytes had been transduced with HC-K ${ }^{\mathrm{d}}$-YCAC $(324,347$ and 36 unique peptides respectively), compared with TAP-sufficient hepatocytes transduced with $\mathrm{HC}-\mathrm{K}^{\mathrm{d}}$ (880 unique peptides) (Figure $7 \mathrm{H}$ ). Comparison of the different tissue immunopeptidomes showed that in the 2 settings where skin graft tolerance was achieved in wild-type recipient mice following expression of allogeneic donor MHC I in hepatocytes, the proportion of skin peptides common to hepatocytes was $43 \%$ and $45 \%$ for $\mathrm{H}-2 \mathrm{~K}^{\mathrm{d}}$ (Figure $7 \mathrm{~B}$ ) and $\mathrm{H}-2 \mathrm{~K}^{\mathrm{b}}$ (Figure 7C), respectively. Conversely, only $1.6 \%$ of skin peptides was also found in Tap1KOHep hepatocytes transduced with HC- $\mathrm{K}^{\mathrm{d}-Y C A C}$, while in the 2 groups with intermediate graft survival (Tap1 $1^{\mathrm{f} / \mathrm{fl}}$ or C57BL/6 inoculated with $\left.\mathrm{HC}-\mathrm{K}^{\mathrm{d}}-\mathrm{YCAC}\right)$, the proportion of skin peptides present in hepatocytes was in the order of $15 \%$ to $17 \%$. Gene ontology analysis of source proteins is shown in Supplemental Figure 6.

$H-2 K^{b}$ peptides from the common peptide pool are recognized by activated alloreactive $C D 8^{+} T$ cells. A total of 100 peptides were selected for screening (listed in Supplemental Table 4). Ninety-six peptides were drawn from the common peptide pool, and their identity was confirmed by a direct comparison between the mass spectra obtained from synthetic and eluted natural peptides (Supplemental Figure 8). An additional 4 peptides had been previously identified as alloreactive $\mathrm{CD} 8^{+} \mathrm{T}$ cell epitopes in B10.BR mice (11, 25). Three of these 4 epitopes were detected within the common 


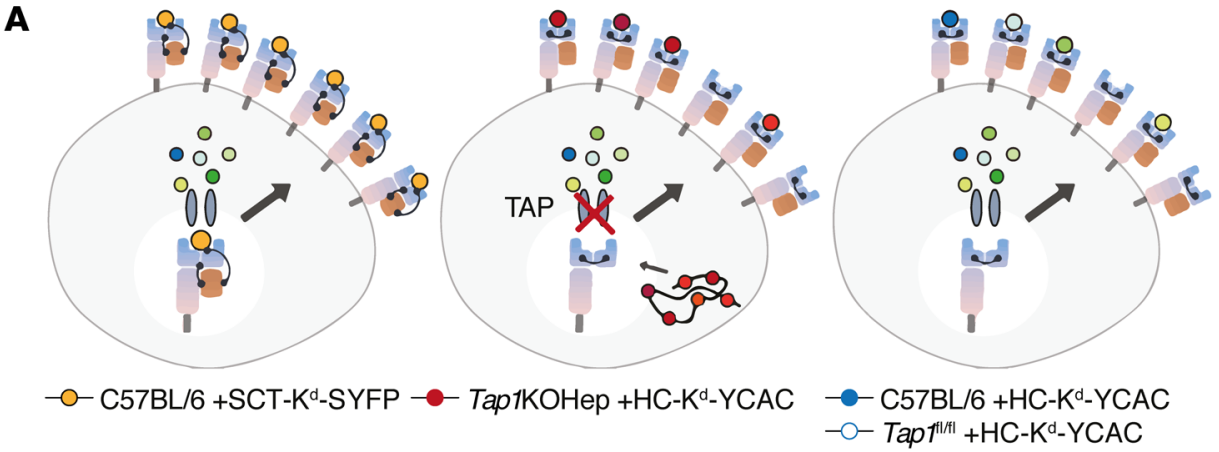

Altered peptide repertoire

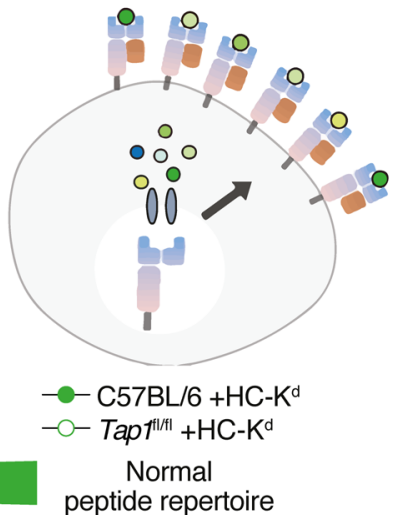

peptide repertoire

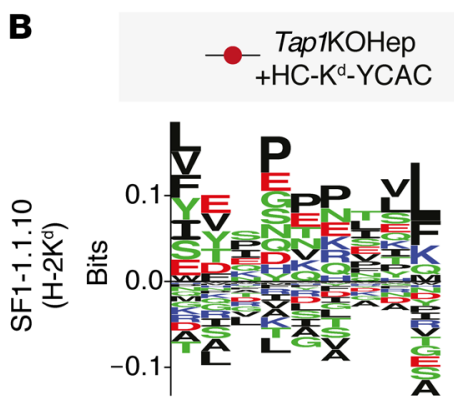

N123456789 C

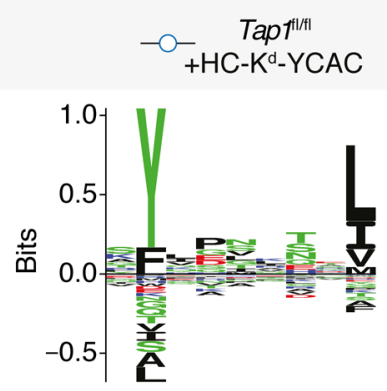

N123456789C

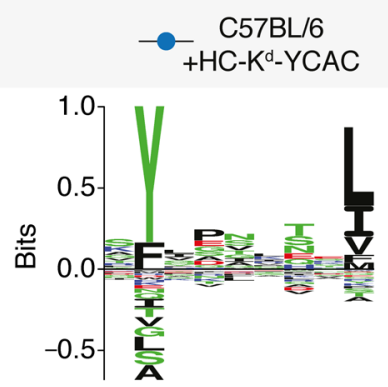

N123456789C
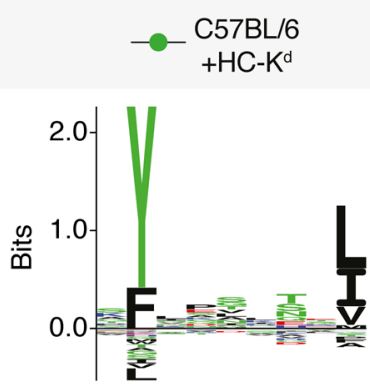

N123456789C
C

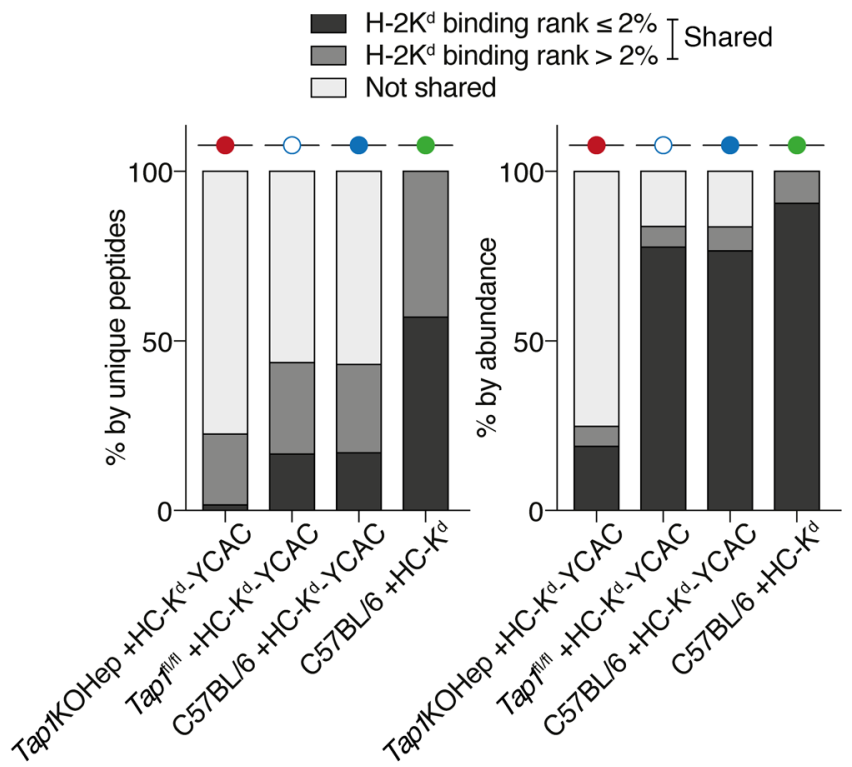

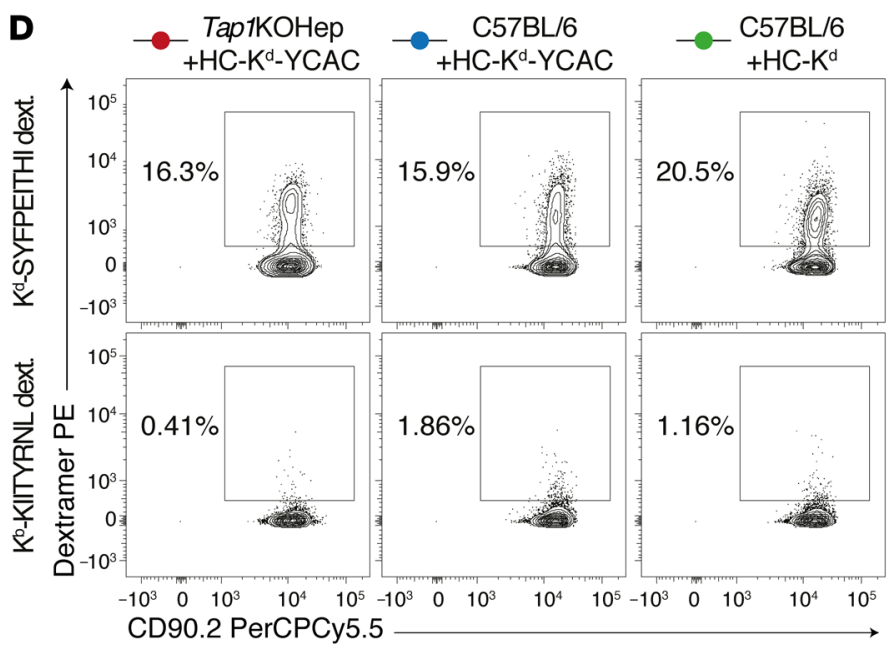

Figure 5. TAP-deficient hepatocytes transduced with AAV-K $K^{\mathrm{d}}-\mathbf{Y C A C}$ present an abnormal peptide repertoire. (A) Differences in peptide presentation between TAP-sufficient and -deficient hepatocytes transduced with AAV vectors encoding one of $3 \mathrm{H}-2 \mathrm{~K}^{\mathrm{d}}$ constructs. From left to right, diagrams show a single presented peptide (SYFPEITHI), a substantially altered repertoire resulting from the combination of $\mathrm{K}^{\mathrm{d}}$-YCAC expression and absence of TAP, a moderately altered repertoire when $\mathrm{K}^{\mathrm{d}}-\mathrm{YCAC}$ is expressed in cells where TAP is active, and the repertoire normally associated with $\mathrm{K}^{\mathrm{d}}$ in TAP-sufficient hepatocytes. Both empty and peptide-loaded $\mathrm{K}^{\mathrm{d}}-\mathrm{YCAC}$ molecules are expected to be present at the cell surface. (B) $\mathrm{H} 2-\mathrm{K}^{\mathrm{d}}$-binding motifs were generated from a nonredundant list of 9-mer peptides using GibbsCluster 2.0. Peptides eluted from B6/HC, B6/YCAC, or Tap7 $7^{\text {fl/fl } / Y C A C ~ h e p a t o c y t e s ~ d i s p l a y e d ~ t h e ~}$ canonical $\mathrm{K}^{\mathrm{d}}$ binding motif of tyrosine $(\mathrm{Y})$ at position 2 and leucine $(\mathrm{L})$ or isoleucine $(\mathrm{I})$ at the $\mathrm{C}$-terminus while no clear binding motif was discernible in the sequences for peptides eluted from Tap1KO/YCAC hepatocytes. (C) Just under $45 \%$ of peptides eluted from B6/YCAC or Tap1 $7^{\text {fl/fi } / Y C A C ~ h e p a t o c y t e s ~}$ were common to the B6/HC repertoire, while only $22 \%$ of peptides from Tap1KO/YCAC were shared with B6/HC. Similarity across peptide repertoires was increased when the comparison was weighted for peptide abundance. The peptide SYFPEITHI was present in all repertoires. (D) Comparable proportions of activated $C D 8^{+} T$ cells able to recognize $\mathrm{K}^{\mathrm{d}}-\mathrm{SYFPEITHI}$ were detected among the liver leukocytes of primed $\mathrm{C} 57 \mathrm{BL} / 6$ mice inoculated with $\mathrm{AAV}$-HC- $\mathrm{K}^{\mathrm{d}}$ or AAV-HC- $K^{\mathrm{d}}-Y C A C$ and those of Tap1KOHep mice treated with AAV-HC- $K^{\mathrm{d}}-\mathrm{YCAC}$. Representative flow plots from $n=3$ are shown. 

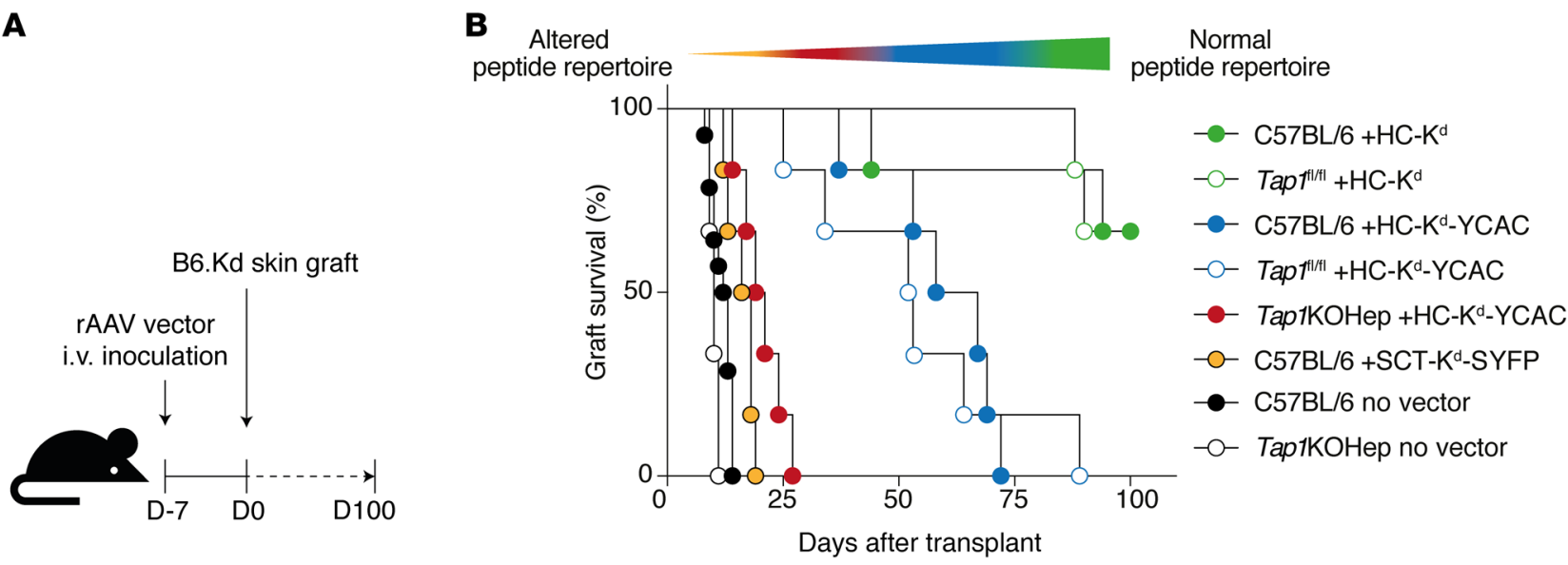

Figure 6. Alteration in the endogenous peptide repertoire impedes transplantation tolerance induction. (A) Tap1KOHep, Tap $7^{\mathrm{fl} / \mathrm{fl}}$, or C57BL6 mice were inoculated with AAV-HC- $\mathrm{K}^{\mathrm{d}}-\mathrm{YCAC}$ or were not transduced. Another group of C57BL/6 were transduced with AAV-SCT-K ${ }^{\mathrm{d}}-\mathrm{SYFP}$, while C57BL6 and Tap $7^{\mathrm{fl} /}$ ${ }^{\mathrm{fl}}$ controls received AAV-HC- $\mathrm{K}^{\mathrm{d}}$. Seven days after inoculation, the mice were challenged with B6.Kd skin grafts. (B) Expression of HC- $\mathrm{K}^{\mathrm{d}}$ loaded with the

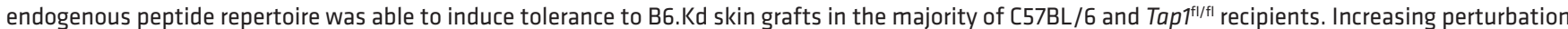
of the $\mathrm{H}-2 \mathrm{~K}^{\mathrm{d}}$-bound peptide repertoire progressively shortened graft survival of $\mathrm{H}-2 \mathrm{~K}^{\mathrm{d}}$-bearing skin grafts. C57BL/6 inoculated with AAV-HC- $\mathrm{K}^{\mathrm{d}}$ (MST: indefinite), C57BL/6 inoculated with AAV-HC-Kd $-Y C A C$ (MST: 62.5 days), Tap $7^{\text {fl/fl }}$ inoculated with AAV-HC-Kd-YCAC (MST: 52.5 days), Tap1KOHep inoculated with AAV-HC-Kd-YCAC (MST: 20 days).Mantel-Cox log-rank test for trend $P<0.0001$, all groups $n=6$.

pool. Binding of pMHC tetramers was used to determine which peptides combined with $\mathrm{H}-2 \mathrm{~K}^{\mathrm{b}}$ to form immunogenic epitopes recognized by alloreactive B10.BR CD8 ${ }^{+} \mathrm{T}$ cells. B10.BR mice were first primed by placement of a $\mathrm{K}^{\mathrm{b}}$-bearing 178.3 skin graft. Approximately 30 days after graft rejection, mice were inoculated with $\mathrm{HC}-\mathrm{K}^{\mathrm{b}}$, and after an additional 7 days, liver leukocytes were isolated and stained by flow cytometry (Figure 8A). The gating strategy is shown in Figure $8 \mathrm{~B}$. Activated $\mathrm{CD} 8^{+} \mathrm{T}$ cells were defined as CD $44^{+} \mathrm{PD}-1^{\text {hi }}$, whereas PD- $1^{-}$cells were considered to be an internal control population which had been exposed in vivo to $\mathrm{H}-2 \mathrm{~K}^{\mathrm{b}}$ expressed on hepatocytes but was not activated. Peptides were deemed immunogenic when at least $2 \%$ of $\mathrm{CD} 44^{+} \mathrm{PD}-1^{\text {hi }} \mathrm{CD} 8^{+} \mathrm{T}$ cells were bound by $\mathrm{pMHC}$ tetramer. Representative flow plots demonstrating $\mathrm{T}$ cell recognition of immunogenic and nonimmunogenic peptides are shown in Figure 8C, while data summarizing the results are shown in Figure 9A and Supplemental Table 4. Allorecognition of $\mathrm{K}^{\mathrm{b}}$-bound peptides was then examined in recipient mice of a second background haplotype (BALB/c, H-2 ${ }^{\mathrm{d}}$ ) (Figure 9, A and B and Supplemental Table 4).

Of 100 peptides screened, 17 peptides were recognized by greater than $5 \%$ of activated recipient $\mathrm{CD}^{+} \mathrm{T}$ cells from male B10.BR mice (termed strongly immunogenic), and an additional 39 were bound by $2 \%-5 \%$ of cells (moderately immunogenic). These responses were mirrored in female B10.BR recipients (Figure $9, \mathrm{~A}$ and B). A number of $\mathrm{pMHC}$ epitopes were recognized by BALB/c mice as well as B10.BR (Figure 9, A and B). All peptides recognized by greater than $5 \%$ of $B 10 . B R$ responder cells and 42 of 43 of those binding greater than $5 \%$ of $\mathrm{BALB} / \mathrm{c}$ cells were 8 -mers. For 8-mer peptides, there was a strong correlation between overall peptide abundance (as estimated by the product of the spectral intensity across the 3 tissue types) and the percentage of T cells with specificity for a given pMHC $(r=0.52, P<0.0001$; Figure $9 C)$. No such relationship was observed for 9-mers. Predicted peptide binding affinity for $\mathrm{H}-2 \mathrm{~K}^{\mathrm{b}}$ (measured by $\mathrm{IC}_{50}$ ) did not differ significantly between strongly, moderately or nonimmunogenic peptides (Figure 9D; $P=0.098$ by 1-way ANOVA), nor was a correlation observed between $\mathrm{IC}_{50}$ and spectral abundance (Figure 9E). Simultaneous staining with 2 different pMHC tetramers was used to evaluate the proportion of $\mathrm{T}$ cells recognizing more than 1 pMHC specificity (Figure 10A), with a total of 6 peptides being evaluated. A substantial proportion of $\mathrm{T}$ cells recognized 2 peptides (SGYIYHKL and/or SVYVYKVL) in addition to SNYLFTKL. A total of $86.7 \% \pm 19.2 \%$ of $\mathrm{T}$ cells recognizing SGYIYHKL-PE could recognize SNYLFTKL-APC and $66.8 \% \pm 9.0 \%$ of T cells recognizing SVYVYKVL-PE could also recognize SNYLFKTKL-APC, whereas cross-reactivity between VGPRYTNL, INFDFPKL, and RTYTYEKL was considerably lower (Figure 10, B and C). When 5 of these 6 peptides (excluding SGYIYHKL), each binding between $7.2 \%$ and $15.2 \%$ of $\mathrm{T}$ cells, were used together as a panel, the proportion of alloreactive CD8 ${ }^{+} \mathrm{T}$ cells bound increased to $39.1 \% \pm$ 3.4\% (Figure 10, D and E; $P<0.0001$ compared with SNYLFTKL). This cumulative increase in binding is consistent with alloreactive $\mathrm{T}$ cell recognition of epitopes comprising both a self-peptide and allogeneic MHC I molecule.

A pMHC tetramer panel enables mechanistic insights into transplant immune responses. We used the 5-tetramer panel (above) to enumerate and phenotype alloreactive $\mathrm{CD}^{+} \mathrm{T}$ cells in a model of secondary skin graft tolerance or rejection (Figure 11A). Gating strategy is shown in Supplemental Figure 9A. Secondary skin grafts to control mice were promptly rejected, while grafts performed 7 days after inoculation of primed recipients with $\mathrm{AAV}-\mathrm{K}^{\mathrm{b}}$ survived indefinitely (Figure 11B). The number of tetramer-positive $\left(\mathrm{tet}^{+}\right)$ $\mathrm{CD}^{+} \mathrm{T}$ cells in combined secondary lymphoid organs expanded 3 -fold following rejection of a secondary skin graft (12,000 \pm 1500 versus $31,000 \pm 3500$ cells, $P=0.0021)$, but had not increased significantly at a matching interval during graft acceptance $(12,000$ \pm 1500 against $22,000 \pm 3700, P=0.29$; Figure $11 \mathrm{C}$ ). Induction of tolerance in primed mice by inoculation with AAV- $\mathrm{K}^{\mathrm{b}}$ resulted 
A Recipient hepatocytes +donor $\mathrm{MHC}\left(\mathrm{K}^{\mathrm{d}}\right.$ or $\left.\mathrm{K}^{\mathrm{b}}\right)$

Donor skin graft $\left(\mathrm{K}^{\mathrm{d}}\right.$ or $\mathrm{K}^{\mathrm{b}}$ )

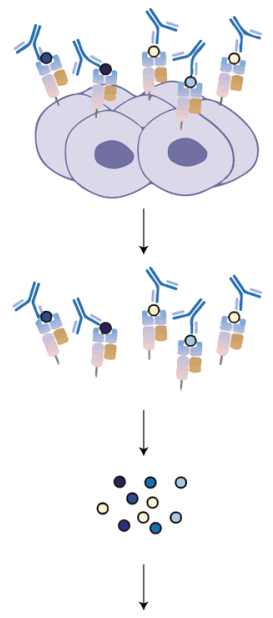

LC-MS/MS
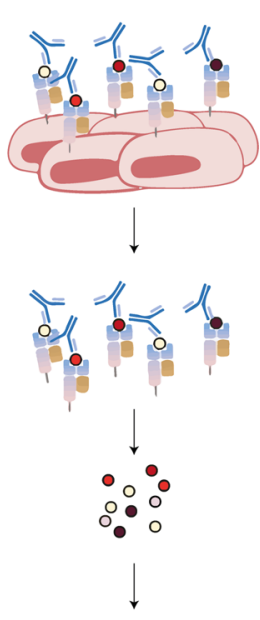

LC-MS/MS

D

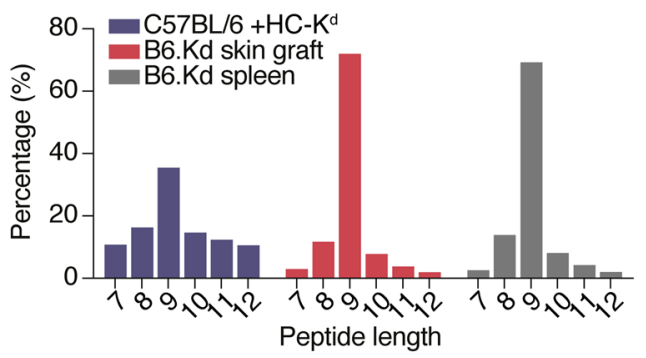

$\mathbf{F}$

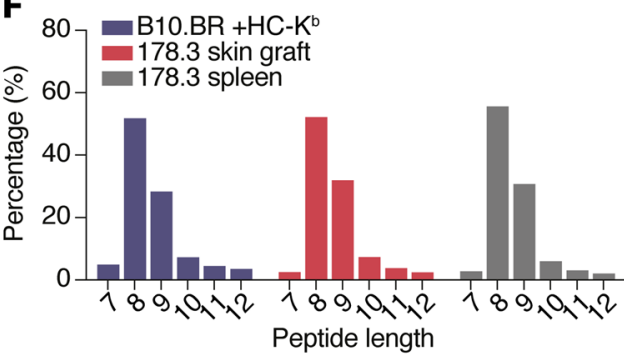

Donor spleen $\left(\mathrm{K}^{\mathrm{d}}\right.$ or $\left.\mathrm{K}^{\mathrm{b}}\right)$

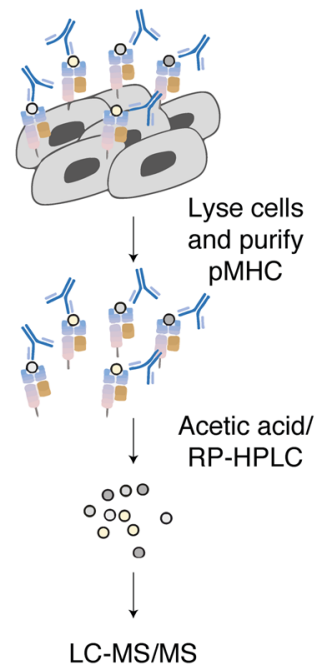

B $\mathrm{C} 57 \mathrm{BL} / 6+\mathrm{HC}-\mathrm{K}^{\mathrm{d}}$ hepatocytes (2452)

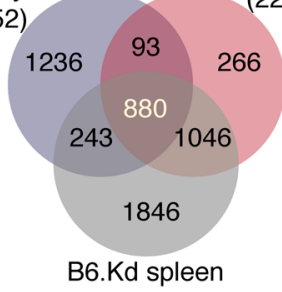

(4015)

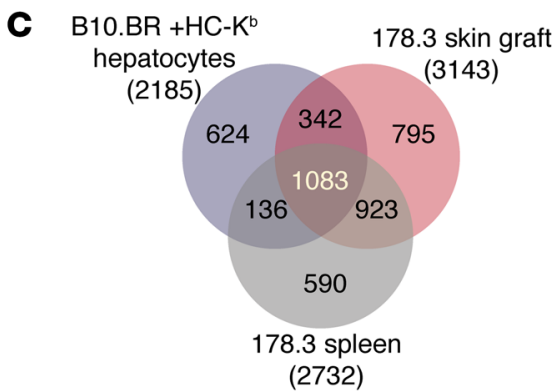

$\mathbf{E}$
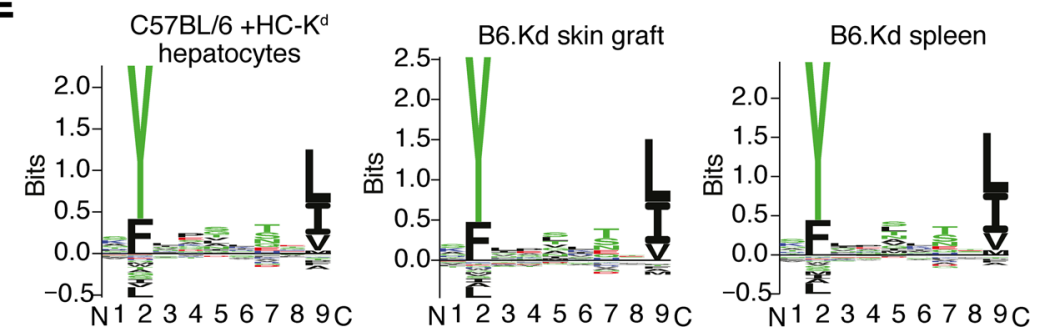

$\mathbf{G}$

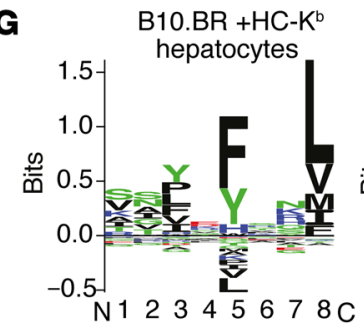

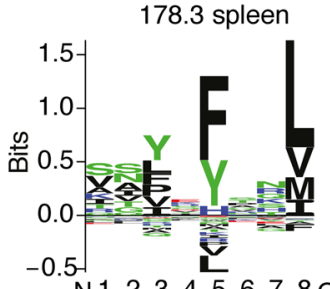

N1 $2345678 \mathrm{C}$

H

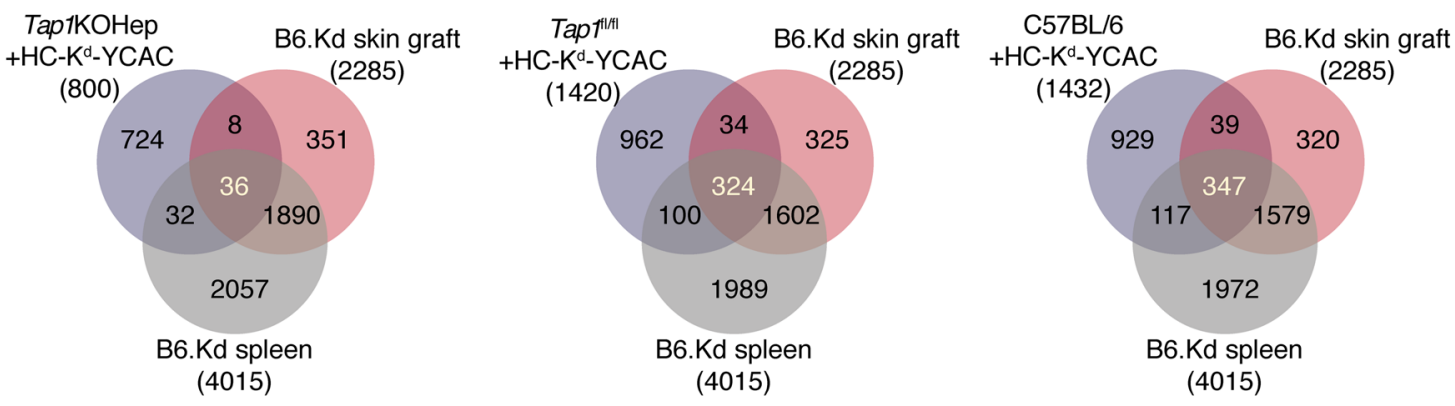


Figure 7. Profiling of the $\mathrm{H}-2 \mathrm{~K}^{\mathrm{d}}$ - and $\mathrm{H}-2 \mathrm{~K}^{\mathrm{b}}$-associated peptide repertoires of transduced hepatocytes, skin, and spleen. (A) A schematic diagram illustrating the immunoaffinity purification workflow. (B and $\mathbf{C}$ ) Unique peptides were identified from transduced hepatocytes, skin, and spleen.

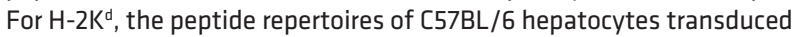
with AAV-HC-Kd, B6.Kd spleen, and B6.Kd skin grafts collected 7 days after transplantation were determined, while for $\mathrm{H}-2 \mathrm{~K}^{\mathrm{b}}$, the corresponding tissues were B10.BR hepatocytes transduced with AAV-HC- $K^{\mathrm{b}}, 178.3$ spleen, and 178.3 skin grafts sampled at 7 days after transplant. Data from 2 independent experiments are shown. Within each replicate experiment, samples from 3 to 4 mice were pooled per condition. For $\mathrm{K}^{\mathrm{d}}, 8809$-mer peptides were found to be shared across all 3 tissue types, while $1083 \mathrm{~K}^{\mathrm{b}}$ peptides (8- to $11-$ mer, $\mathrm{IC}_{50}<500 \mathrm{nM}$ ) were common to the 3 tissues. (D) Length distribution of filtered $\mathrm{H}-2 \mathrm{~K}^{\mathrm{d}}$ peptides from hepatocytes, spleen, and skin graft tissue samples. The number of peptides of each length identified with a 5\% FDR cut-off are shown. (E) Peptide-binding motifs for $\mathrm{H} 2-\mathrm{K}^{\mathrm{d}}$ peptides generated from a nonredundant list of 9 -mer peptides using GibbsCluster 2.0. (F) Length distribution of $\mathrm{H}-2 \mathrm{~K}^{\mathrm{b}}$ peptides from hepatocytes, spleen, and skin graft tissue samples (as for $\mathbf{D}$ ). Most eluted peptides are 8-mers, with 9-mers also relatively frequent. (C) Peptide-binding motifs for $\mathrm{H} 2-\mathrm{K}^{\mathrm{b}}$ peptides generated from a list of 8- to 11-mer peptides using the GibbsCluster 2.0 algorithm as above. The canonical binding motifs were observed for all 3 tissues for both $\mathrm{H}_{2}-\mathrm{K}^{\mathrm{d}}$ and $\mathrm{H} 2-\mathrm{K}^{\mathrm{b}}$. (H) The extent of peptide sharing between the $\mathrm{H} 2-\mathrm{K}^{\mathrm{d}}$ repertoires of hepatocytes, spleen, and skin was substantially reduced when Tap1KOHep, Tap fl/f1 $^{1 / 1}$ or C57BL6 mice

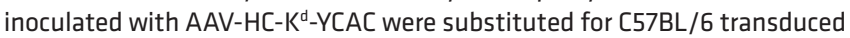
with AAV-HC- $\mathrm{K}^{\mathrm{d}}$. This reduction was particularly striking for the combination of Tap1KOHep with AAV-HC-Kd-YCAC.

in a sharp increase of tet $^{+}$cells within the liver (from $480 \pm 97$ to $131,000 \pm 22,000$ cells, $P<0.0001$ ), declining subsequently (Figure 11D). While the overall number of tet ${ }^{+}$cells on protocol d14 was not significantly greater in rejecting skin grafts than in grafts destined to be accepted $(640 \pm 190$ versus $400 \pm 130$ cells, $P=$ 0.78 ; Figure 11E), rejecting transplants contained a tetramer-bright population (tet ${ }^{\mathrm{hi}}, 12.7 \% \pm 0.97 \%$ of $\mathrm{CD}^{+} \mathrm{T}$ cells) which was not detected in tolerated grafts (Figure 11, F-H). Few tet ${ }^{+}$cells persisted long-term in accepted grafts (Figure 11E). Examining the tet $^{+}$cells revealed phenotypic changes, which were partly obscured within the bulk $\mathrm{CD}^{+}$population. In naive mice, the tet ${ }^{+}$liver leukocytes included all $\mathrm{CD}^{+} \mathrm{T}$ cell subsets, whereas in mice having rejected a primary or secondary graft, tet ${ }^{+}$cells were exclusively antigenexperienced, comprising both central memory and effector/ resident memory-like cells. Following exposure to $\mathrm{H}-2 \mathrm{~K}^{\mathrm{b}}$ in the liver, tet ${ }^{+}$cells with a central memory phenotype were no longer observed, and the majority of cells expressed markers of liverhoming or residency (CD69 and/or CXCR6, Figure 12, A and B and Supplemental Figure 10). By 7 days after inoculation with AAV-K tet $^{+}$cells in the liver have upregulated expression of PD-1, TIGIT, Tim-3, and LAG-3. While strong PD-1 expression persists through d84 after tolerance induction, expression of LAG-3, Tim-3, and to a lesser extent TIGIT in the tet $^{+}$population progressively declines in tandem with the decay of tet ${ }^{+}$cell numbers, consistent with preferential deletion of cells expressing multiple exhaustion markers (Figure 12C and Supplemental Figure 11). All tet ${ }^{+}$cells isolated from rejecting or tolerated grafts on protocol d14 were antigen experienced. Tet ${ }^{\text {hi }}$ cells from rejecting grafts were uniformly CD62Lnegative and PD- $1^{\text {hi }}$, likely denoting recent strong activation of these cells, while the majority of tet ${ }^{+}$cells from tolerated grafts expressed CD62L and not PD-1.

\section{Discussion}

Direct allorecognition refers to the engagement of recipient TCRs by intact allogeneic MHC molecules on the surface of donor cells. In some settings, intact, unprocessed donor MHC is transferred to the surface of recipient APC, a variant known as the semidirect pathway of allorecognition (26). While direct/ semidirect allorecognition is a critical driver of both solid organ allograft rejection (26) and tolerance induction (3), the specific molecular targets of most directly alloreactive $\mathrm{CD} 8^{+} \mathrm{T}$ cells have not been defined, limiting our understanding of these phenomena. In this study, we provide definitive evidence for the contribution of the peptide cargo of allogeneic MHC I molecules to transplant tolerance induction. Moreover, we demonstrate the feasibility of a systematic approach incorporating mass spectrometry-based identification of alloantigen-presented peptides, alloreactive $\mathrm{T}$ cell enrichment, and $\mathrm{pMHC}$ multimer screening for the discovery of pMHC epitopes that are directly recognized by alloreactive $\mathrm{CD} 8^{+} \mathrm{T}$ cells. To our knowledge, this represents the first example of such an approach in the context of direct allorecognition.

Studies over many years using $\mathrm{T}$ cell clones suggested that most directly alloreactive $\mathrm{CD}^{+}$clones recognize allogeneic MHC I molecules complexed with an endogenous peptide, while peptide-independent direct allorecognition was also reported. Our recent finding that direct recognition of hepatocyteexpressed donor MHC I by recipient $\mathrm{CD}^{+} \mathrm{T}$ cells was required for donor skin graft tolerance induction provided us with a unique opportunity to examine the role of the hepatocyte immunopeptidome in transplant tolerance, and by extension, in alloresponses more broadly. We used 2 complementary approaches to separate expression of donor MHC I molecules from presentation of their usual peptide cargo. In the first approach, we utilized an AAV vector encoding $\mathrm{H}-2 \mathrm{~K}^{\mathrm{b}} \mathrm{HC}, \beta 2 \mathrm{~m}$, and the single peptide KIITYRNL to express high levels of $\mathrm{K}^{\mathrm{b}}$ on the surface of recipient hepatocytes, while excluding presentation of naturally processed endogenous peptides. Tolerance to $\mathrm{K}^{\mathrm{b}}$-bearing skin grafts was able to be induced in reconstituted mice with a monoclonal population of $\mathrm{T}$ cells all recognizing the $\mathrm{K}^{\mathrm{b}}$-KIIT epitope, but not in wild-type mice possessing a full TCR repertoire. Second, we expressed a mutated version of the $\mathrm{H}-2 \mathrm{~K}^{\mathrm{d}} \mathrm{HC}$, which is permissive to loading with suboptimal peptides in a purpose-bred mouse strain (Tap1KOHep) with a hepatocyte-specific deletion of Tap1. This combination resulted in a significant alteration of the $\mathrm{K}^{\mathrm{d}}$-bound peptide repertoire and prevented tolerance induction. Graft survival was shortened to a lesser extent in TAP1sufficient mice transduced with $\mathrm{HC}-\mathrm{K}^{\mathrm{d}}-\mathrm{YCAC}$, in keeping with the lesser perturbation of the $\mathrm{K}^{\mathrm{d}}$ peptide repertoire observed in these mice. The point mutations Y84C and A139C in the $\mathrm{K}^{\mathrm{d}} \mathrm{HC}$ permit the creation of a disulphide bridge, which stabilizes the peptide binding groove when empty or populated by a low-affinity peptide (18). The presence of these mutations alters the composition of the $\mathrm{K}^{\mathrm{d}}$-associated peptide repertoire but does not impede $\mathrm{T}$ cell responses to a given pMHC ligand (24). Accordingly, the ubiquitous peptide SYFPEITHI was present within the repertoires of all hepatocytes transduced with either $\mathrm{HC}-\mathrm{K}^{\mathrm{d}}$ or $\mathrm{HC}-\mathrm{K}^{\mathrm{d}}-\mathrm{YCAC}$ and comparable proportions of $\mathrm{T}$ cells isolated from the livers of these mice bound $\mathrm{K}^{\mathrm{d}}$-SYFP dextramers. 

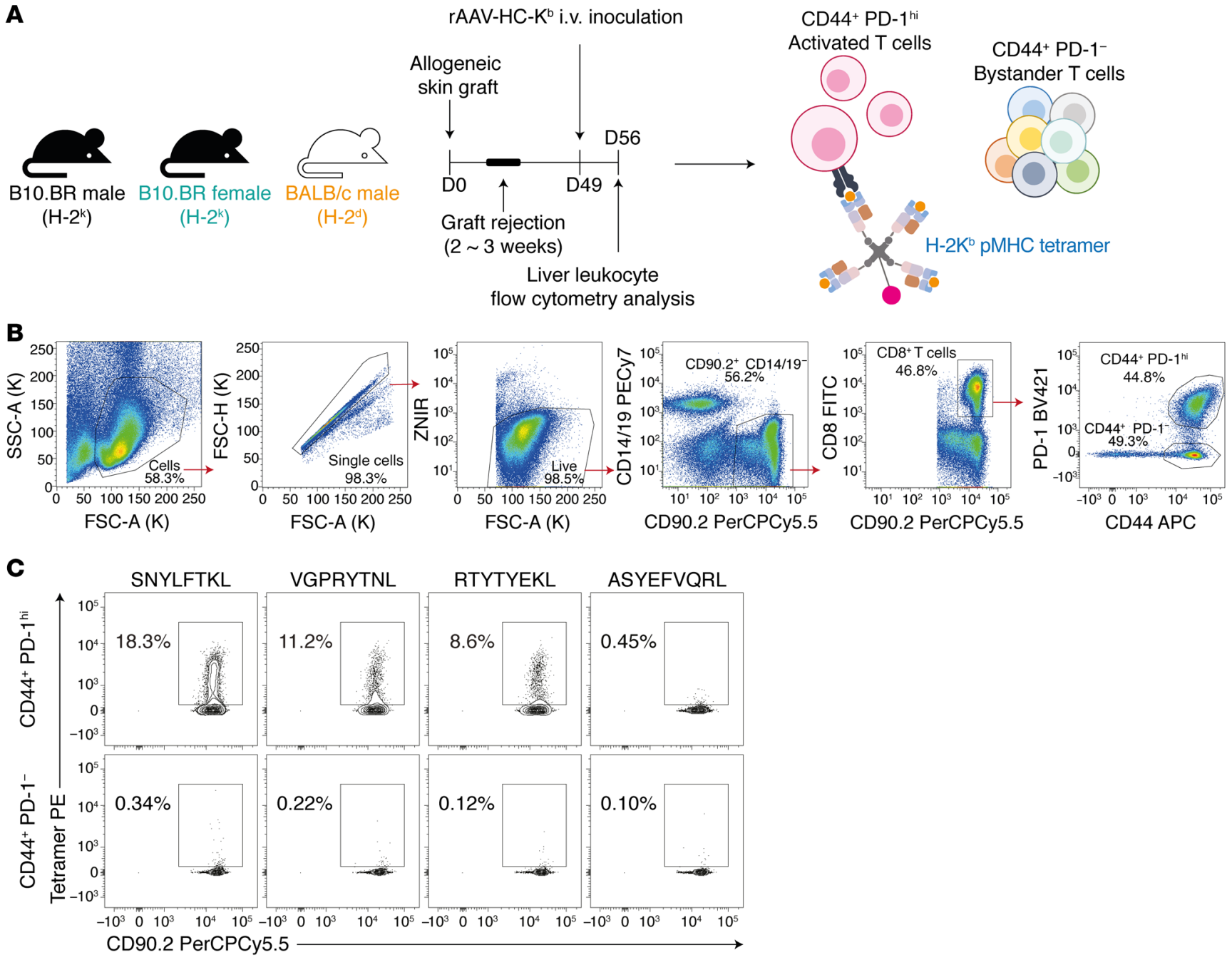

Figure 8. Identification of PMHC epitopes recognized by alloreactive CD8 $\mathbf{T}$ cells. (A) Male B10.BR mice were primed with male 178.3 skin grafts and 30 days after rejection mice were transduced with AAV-HC-K'. Liver leukocytes were isolated and pMHC tetramer binding was analyzed using flow cytometry. (B) Shows the gating strategy that was employed to identify and stratify CD8 ${ }^{+} T$ cells into 2 groups; CD44 $P D-1^{\text {hi }}$ and CD44+PD-1 ${ }^{-}$. CD44+PD- $1^{\text {hi }}$ cells are activated alloreactive $C D 8^{+} T$ cells and $C D 44^{+} \mathrm{PD}-1^{-}$cells are nonactivated bystander $C D 8^{+} T$ cells which serve as internal controls. (C) Examples of pMHC tetramer binding by CD44+PD- $1^{\text {hi }}$ and CD44 $P D-1^{-}$CD8 ${ }^{+} T$ cells. Representative flow plots (from $n=3$ biological replicates) for the selected pMHC epitopes are shown. $\mathrm{K}^{\mathrm{b}}-\mathrm{SNYLFTKL}\left(\mathrm{Epas}_{387-394}\right), \mathrm{K}^{\mathrm{b}}-\mathrm{VGPRYTNL}$ (Mapk1 ${ }_{19-26}$ ), and $\mathrm{K}^{\mathrm{b}}-\mathrm{RTYTYEKL}$ (Ctnnb1 $1_{329-336}$ ) were recognized by a large proportion of activated alloreactive $T$ cells, whereas few T cells bound $K^{\mathrm{b}}-$ ASYEFVQRL (Dync $\left.1 \mathrm{~h} 1_{1379-1387}\right)$.

Having demonstrated the importance of the peptide cargo of allogeneic MHC I molecules for transplant tolerance induction, we set about identifying the subset of peptides responsible for modulating the anti-graft alloresponse, using an immunoproteomic approach to identify and characterize the immunopeptidomes of relevant tissues. We hypothesized that hepatocyte expression of peptides that were also presented by cells in the grafted skin underpinned tolerance induction. Consistent with this hypothesis, in conditions where tolerance was achieved, $43 \%$ of $\mathrm{K}^{\mathrm{d}}$-associated peptides and $45 \%$ of $\mathrm{K}^{\mathrm{b}}$-bound peptides from transduced hepatocytes were also expressed in donor skin. When survival prolongation was minimal, only $1.6 \%$ of hepatocyte $\mathrm{K}^{\mathrm{d}}$-bound peptides were common to donor skin, and this shared proportion increased to $15 \%$ to $17 \%$ in the groups with intermediate graft survival. Recognition of pMHC epitopes shared between hepatocytes and the graft could induce tolerance via deletion, sequestration within the liver, or cell-intrinsic functional inactivation of specific $\mathrm{CD} 8^{+} \mathrm{T}$ cells, preventing them from attacking the skin. These mechanisms may operate in concert, while linked suppression of responses against epitopes expressed exclusively in the skin by $\mathrm{T}$ cells recognizing shared epitopes may also contribute to the induction and maintenance of tolerance.

To identify immunogenic peptides from the shared subset, we generated an enriched population of alloreactive $\mathrm{CD} 8^{+} \mathrm{T}$ cells by priming mice with a skin graft expressing $\mathrm{H}-2 \mathrm{~K}^{\mathrm{b}}$, followed by boosting with a liver-specific AAV vector encoding $\mathrm{HC}-\mathrm{K}^{\mathrm{b}}$. Coexpression of CD44 with high levels of PD-1 allowed us to distinguish between activated cells and bystander cells, which had been exposed to the alloantigens, but had not responded. Of the 100 $\mathrm{K}^{\mathrm{b}}$-binding peptides selected for tetramer screening, 17 were recognized by more than $5 \%$ of the enriched alloreactive $\mathrm{T}$ cell population. INFDFNTI, previously reported to be recognized by a large 


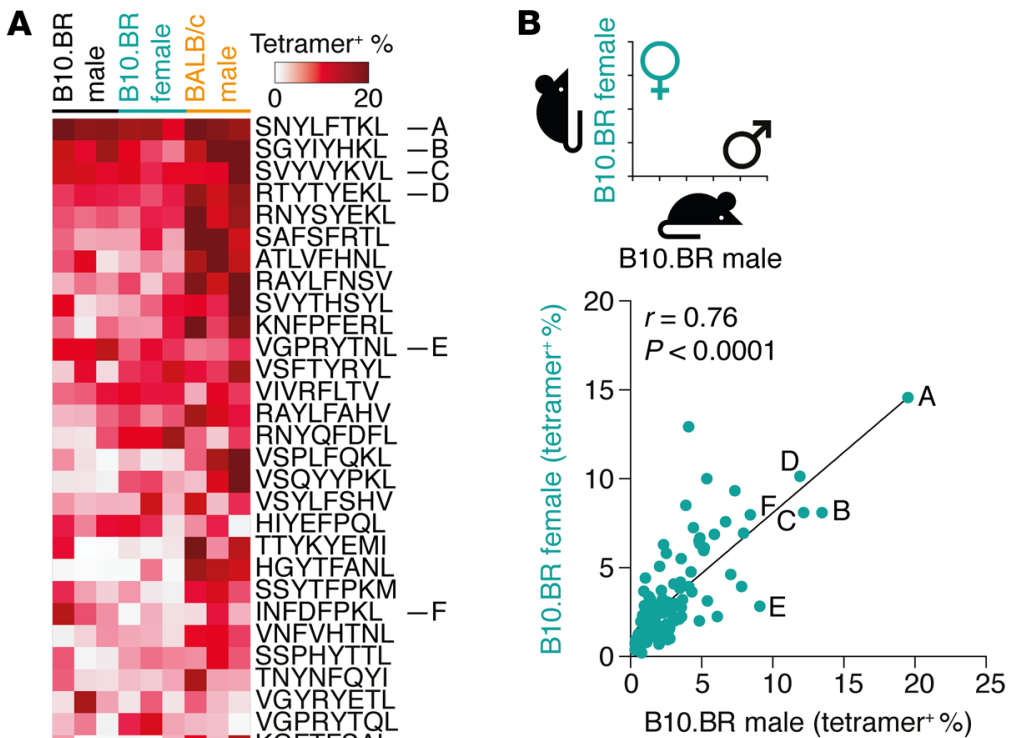

C

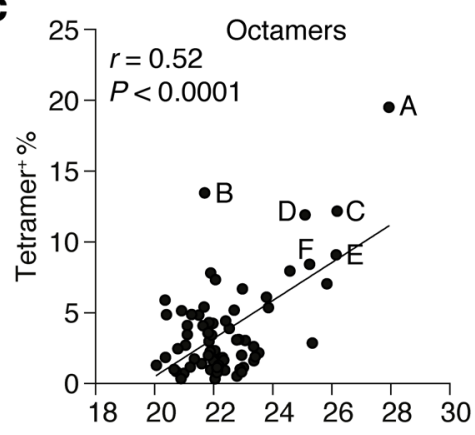

$\log _{10}$ ( $\pi$ of spectral intensity values)

D

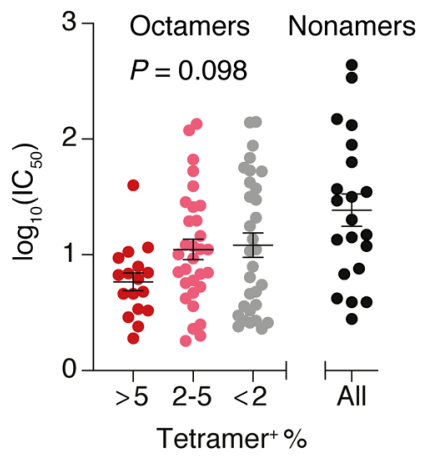

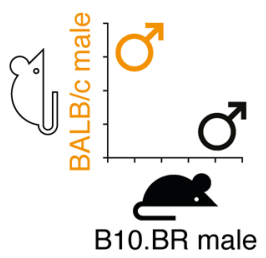
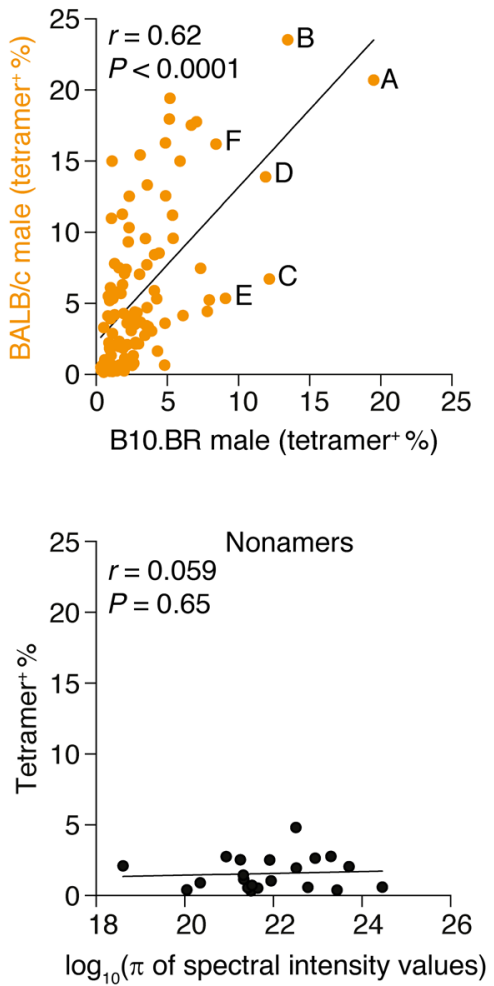

$\mathbf{E}$

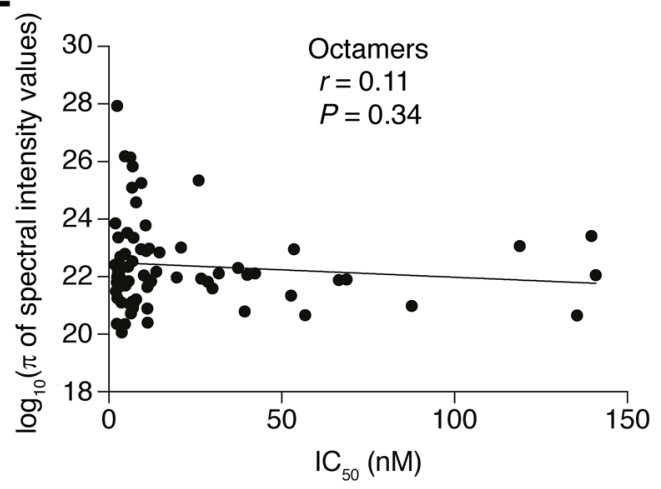


Figure 9. Features of immunogenic $\mathrm{pMHC}$ recognized by mice from different allogeneic backgrounds. (A) One hundred peptides were screened for recognition by activated alloreactive T cells. T cells from female B10.BR mice primed with a female 178.3 skin graft and male BALB/c mice primed with a male $\mathrm{C57BL} / 6$ skin graft were used in parallel with T cells from primed male B10.BR. A heatmap was generated in order to compare recognition of $\mathrm{pMHC}$ epitopes across different sexes and strains. Epitopes are ordered from the top to the bottom by the average of pMHC tetramer binding across all samples. Thirteen pMHCs were recognized by more than $5 \%$ of activated alloreactive T cells across all 3 groups. Full peptide screening data can be found in Supplemental Table 4. (B) Strong correlation of T cell binding to each pMHC was found between male and female B10.BR (Pearson correlation coefficient, $r=0.76, P<0.0001$ ) and between male B10.BR and male BALB/c $(r=0.62, P<0.0001)$. (C) For male B10.BR mice, the proportion of T cells binding 8-mer $\mathrm{PMHC}$ tetramers was proportional to $\log _{10}$ of the product of the spectral intensity values for each peptide across 3 different tissues $(r=0.52, P<0.0001)$. Conversely, binding to 9-mer pMHC tetramers did not correlate with peptide spectral intensity $(r=0.059, P=$ 0.65 ). For each pMHC epitope, data were obtained from 1 to 2 independent experiments with a total of 3 biological replicates. (D) Predicted peptide binding affinity for $\mathrm{H}-2 \mathrm{~K}^{\mathrm{b}}$ (measured by $\mathrm{IC}_{50}$ ) did not differ significantly between strongly, moderately, or nonimmunogenic peptides $(P=0.098$ by 1-way ANOVA, mean \pm SEM are shown), (E) nor was a correlation observed between $\mathrm{IC}_{50}$ and spectral intensity values $(r=0.11, P=0.34)$.

proportion of the polyclonal alloreactive $\mathrm{T}$ cell population of $\mathrm{B} 10$. BR mice (25), was bound by an average of $3.7 \%$ of male B10.BR cells. To examine factors that might contribute to the immunogenicity of different $\mathrm{pMHC}$, we used spectral intensity as an approximation for relative peptide abundance and $\mathrm{IC}_{50}$ to predict binding affinity of the peptide for $\mathrm{H}-2 \mathrm{~K}^{\mathrm{b}}$. An overall measure of abundance was derived by multiplying the spectral intensity recorded in each of the 3 tissues. For 8-mer peptides, a strong correlation was found between abundance and the proportion of $\mathrm{CD}^{+} \mathrm{T}$ cells recognizing particular peptides. This is at variance with observations of $\mathrm{CD}^{+} \mathrm{T}$ cell recognition of $\mathrm{K}^{\mathrm{b}}$-associated viral epitopes, where the frequency of $\mathrm{T}$ cells responding to a given epitope corresponds weakly at best to epitope abundance $(27,28)$. In contrast, while there was a tendency for the strongly immunogenic peptides to have high predicted affinity for $\mathrm{K}^{\mathrm{b}}$, there was no significant difference in $\mathrm{IC}_{50}$ between the strongly, moderately, and nonimmunogenic groups, nor was there an association between $\mathrm{IC}_{50}$ and peptide abundance. While a prediction of immunogenicity based on peptide abundance is no substitute for direct measurement, these findings suggest that the likelihood of finding strongly immunogenic peptides is greater if the search is targeted toward the most highly represented peptide species. The relationship between abundance and immunogenicity did not apply to 9-mer peptides.

One intriguing finding of this study was the broad overlap between strongly immunogenic $\mathrm{K}^{\mathrm{b}}$-peptide epitopes recognized by BALB/c and those first identified in B10.BR mice (13/17 peptides). Further studies in mouse and human subjects will be needed to establish the prevalence of such "super-epitopes" recognized by allogeneic $\mathrm{T}$ cells across several genetic backgrounds. While extensive cross-reactivity is a feature of self MHC-restricted T cells, the range of possible cross-reactive epitopes is constrained by peptide length, with $\mathrm{T}$ cell clonotypes showing a strong preference for a single length peptide (29). Alloreactive $\mathrm{T}$ cell clones have undergone positive selection during thymic development based on self-MHC. The majority of peptides eluted from $\mathrm{H}-2 \mathrm{~K}^{\mathrm{k}}$ are 8-mers (ref. 30 and Supplemental Table 1) which aligns with the result that in male B10.BR mice $\left(\mathrm{H}-2^{\mathrm{k}}\right) 17$ of 79 8-mer peptides but 0 of 219 -mers were strongly immunogenic. Most peptides associated with the $\mathrm{H}-2^{\mathrm{d}}$ allomorphs $\mathrm{D}^{\mathrm{d}}, \mathrm{L}^{\mathrm{d}}$, and $\mathrm{K}^{\mathrm{d}}$ are nonamers (30), yet 42 of 79 8-mers and only 1 of 21 9-mers were strongly immunogenic in BALB/c $\left(\mathrm{H}-2^{\mathrm{d}}\right)$ mice. Possible explanations for this asymmetry are that cross-reactivity involving an allogeneic MHC molecule is not subject to the same peptide length limitations as cross-reactivity between self-MHC-restricted peptide epitopes, or that a small number of octamer-preferring $\mathrm{CD} 8^{+} \mathrm{T}$ cells from $\mathrm{BALB} / \mathrm{c}$ mice expand preferentially in the presence of $\mathrm{H}-2 \mathrm{~K}^{\mathrm{b}}$ presenting mainly 8 -mers. While the mean $\mathrm{H}-2 \mathrm{~K}^{\mathrm{b}} \mathrm{IC}_{50}$ among the 9-mer peptides was greater than that of the 8-mers, a number of 9-mer peptides were in the same $\mathrm{IC}_{50}$ range as the strongly immunogenic 8-mers, so this is unlikely to fully explain the reduced frequency of recognition of 9-mer peptides.

A staining panel comprising only 5 strongly immunogenic pMHC epitopes identified nearly $40 \%$ of $\mathrm{T}$ cells in an enriched alloreactive population; we then used this panel to enumerate and phenotype alloreactive $\mathrm{T}$ cells in our model of secondary skin graft rejection or tolerance, thereby seeking insights into the mechanisms promoting tolerance. Tolerance induction upon $\mathrm{AAV}-\mathrm{K}^{\mathrm{b}}$ inoculation is accompanied by a rapid increase of tet $^{+} \mathrm{T}$ cells within the liver, decaying over subsequent weeks, similar to the kinetics of tolerance induction following administration of recombinant adenovirus expressing $\beta$-galactosidase (31). As tet ${ }^{+}$ $\mathrm{T}$ cell numbers decline, the proportion of the population expressing Tim- 3 and LAG-3 decreases, while PD- 1 and TIGIT expression persists. Cells expressing multiple coinhibitory receptors may be preferentially deleted, while the remaining cells are functionally silenced $(1,31)$. While the number of tet ${ }^{+}$cells was not significantly greater in rejecting skin grafts than in grafts destined to be accepted, a tetramer-bright population of $\mathrm{CD}^{+} \mathrm{T}$ cells was exclusively present in the rejecting grafts. Absence of these tet ${ }^{\text {ti }}$ cells from the tolerated grafts could reflect their deletion or sequestration in the liver following antigen encounter, or a difference in the avidity profiles of clones expanded after activation in different sites. Of note, reduced functional avidity of polyclonal alloreactive $\mathrm{T}$ cells was observed in mice accepting heart grafts after donor cell infusion and costimulatory blockade (32). There was minimal persistence of alloreactive CD ${ }^{+} \mathrm{T}$ cells within permanently accepted skin grafts. Tracking the evolution of the alloreactive TCR repertoire during rejection, emerging and established tolerance would provide definitive evidence for the expansion and/or deletion of particular clonotypes, and could be coupled with gene expression analysis and avidity measurements. Future experiments could address the contribution of linked suppression to the induction or maintenance of tolerance. Whether or not the performance of a tetramer panel developed using a skin-graft model will be replicated in solid organ transplants or graft versus host disease remains to be determined.

The findings of this study open a number of avenues for future research. First, they suggest an approach for the systematic discovery of pMHC epitopes for directly alloreactive $\mathrm{CD} 8^{+} \mathrm{T}$ cells, which may be adapted to additional MHC I allomorphs in mice, humans, and other species. Identification of large numbers of allogeneic $\mathrm{pMHC}$ epitopes will enable the characterization of alloreac- 


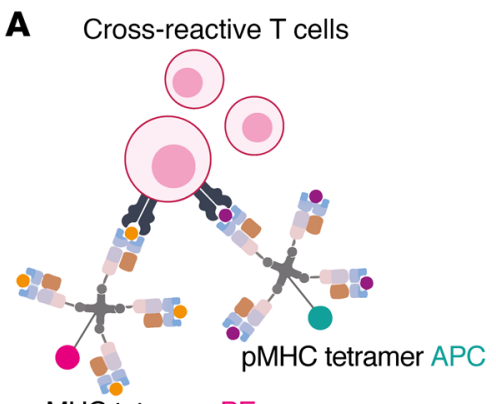

pMHC tetramer PE
B
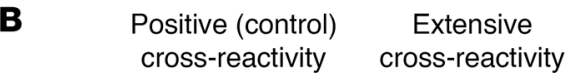

Peptide B

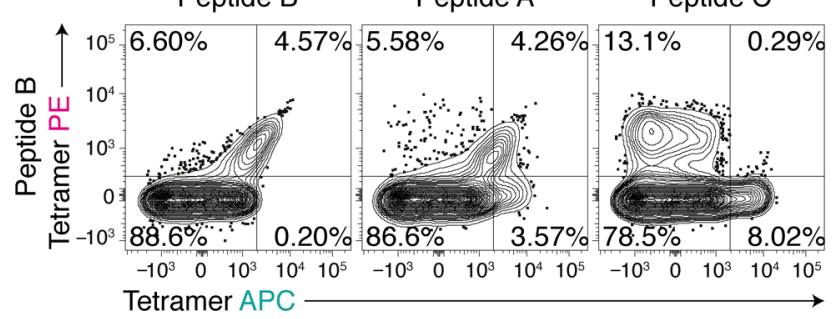

C

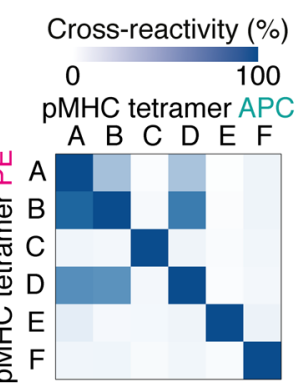

D

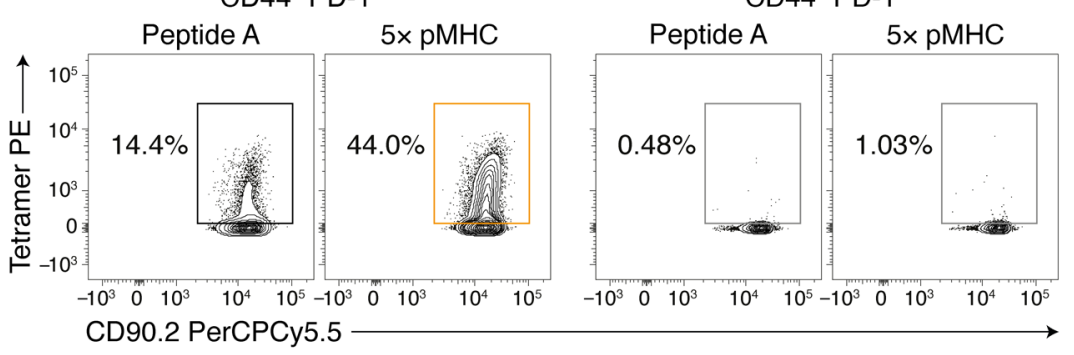

$(0.5 \mu \mathrm{g} / 100 \mu \mathrm{L}$ for each pMHC epitope)
E

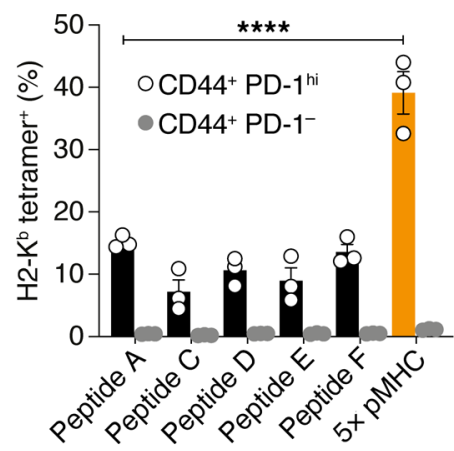

Figure 10. pMHC multimers can be combined to enhance detection of alloreactive T cells within a polyclonal population. (A and B) Staining with 2 different pMHC tetramers was used to evaluate the proportion of T cells recognizing more than $1 \mathrm{pMHC}$ specificity. Six strongly immunogenic peptides were tested; $86.7 \% \pm 19.2 \%$ of SNYLFTKL ${ }^{+}$T cells recognized SGYIYHKL in addition to SNYLFTKL, while SVYVYKVL tetramers bound $66.8 \% \pm 9.0 \%$ of SNYLFT$\mathrm{KL}^{+} \mathrm{T}$ cells and SGYIYHKL tetramers bound $75.8 \% \pm 18.5 \%$ of SVYVYKVL+ cells. Cross-reactivity between VGPRYTNL, INFDFPKL, and RTYTYEKL was considerably lower $(4.0 \% \pm 1.1 \%$ and $8.4 \% \pm 0.6 \%$ of T cells recognized VGPRYTNL in addition to INFDFPKL and RTYTYEKL, respectively). (B) Representative flow plots from 2 independent experiments with 3 to 4 mice pooled/experiment. (C) A heatmap was generated in order to compare cross-reactivity between different pMHC epitopes. ( $\mathbf{D}$ and $\mathbf{E}$ ) When 5 of these 6 peptides (excluding SCYIYHKL), each binding between $7.2 \%$ and $15.2 \%$ of T cells were used together as a panel, the proportion of alloreactive CD8 ${ }^{+}$T cells bound increased to $39.1 \% \pm 3.4 \%(P<0.0001)$ compared with $15.2 \% \pm 0.6 \%$ for SNYLFTKL. Data were obtained from 1 experiment with $n=3$ biological replicates/group. (D) Representative flow plots (from $n=3$ ). (E) Data are shown as mean \pm SEM, statistical analysis comprised 1-way ANOVA in conjunction with Sidak's multiple comparison test: ${ }^{* * *} P<0.0001$.

tive TCR repertoires, including biophysical and structural studies with many more receptor-ligand pairs than the handful currently known, which in turn will provide further insights into the fundamental basis of alloreactivity. Systematic allogeneic pMHC epitope discovery is complemented by the recent advent of methodologies such as oligonucleotide barcoding permitting the use of pMHC multimers for parallel tracking and enumeration of more than 1000 individual pMHC specificities, with options for coupling to single-cell TCR sequence and gene expression analyses $(33,34)$. pMHC multimers conjugated with radionuclides are sensitive tools that could be applied to in vivo imaging of specific alloresponses (35). Beyond their potential as research reagents, allospecific pMHC multimers could enhance posttransplant immune monitoring and immunophenotyping of directly alloreactive $\mathrm{T}$ cells in a clinical setting. Finally, pMHC multimers are not only reagents for antigen-specific $\mathrm{T}$ cell detection, but potential vehicles for antigen-specific therapy, which may be employed for the depletion or immunomodulation of alloreactive T cells (36). In conclusion, the findings of this study represent a significant advance in our understanding of the role of endogenous peptides in direct $\mathrm{T}$ cell alloreactivity, enabling exploration of the alloreactive $\mathrm{T}$ cell repertoire and potential translation to clinically applicable tools.

\section{Methods}

Peptides, antibodies, and reagents. Peptides were synthesized with an average of $98 \%$ purity (GL Biochem Shanghai Ltd.). Lyophilized peptides were reconstituted in $10 \% \mathrm{DMSO}$ and stored at $-80^{\circ} \mathrm{C}$. Dasatinib (Sigma-Aldrich, catalog CDSO23389) was reconstituted in DMSO and $5 \mathrm{mM}$ stock was stored at $-80^{\circ} \mathrm{C}$. Primary and secondary antibodies used in this study are shown in Supplemental Table 5.

Cell lines. The Tap2-deficient T lymphoma cell line RMA-S (provided by Klas Kärre, Karolinska Institutet, Stockholm, Sweden) was cultured in RPMI-1640 medium supplemented with L-glutamine (Lonza, catalog 12-702F), penicillin-streptomycin (Invitrogen, catalog 15140), and 10\% FCS (Sigma-Aldrich, catalog 13K179) at $37^{\circ} \mathrm{C}$ with $5 \% \mathrm{CO}_{2}$.

RMA-S peptide stabilization and transfection. RMA-S cells were grown to confluence and passaged to a concentration of $3 \times 10^{5}$ cells/ $\mathrm{mL}$ then transferred to flat-bottomed 24-well culture plates. The cells were incubated at $27^{\circ} \mathrm{C}$ for 20 hours with $5 \% \mathrm{CO}_{2}$, then pulsed with peptides at concentrations ranging from 0.0001-10 $\mu \mathrm{M}$. Following 1 hour incubation at $27^{\circ} \mathrm{C}$, cells were returned to $37^{\circ} \mathrm{C}$ for 2 hours. Surface expression of stabilized $\mathrm{H}-2 \mathrm{~K}^{\mathrm{b}}$ was quantified using flow cytometry with the conformation-dependent mAb Y-3. For transient transfection of RMA-S cells, $2 \times 10^{6}$ cells were nucleofected with 2 
A
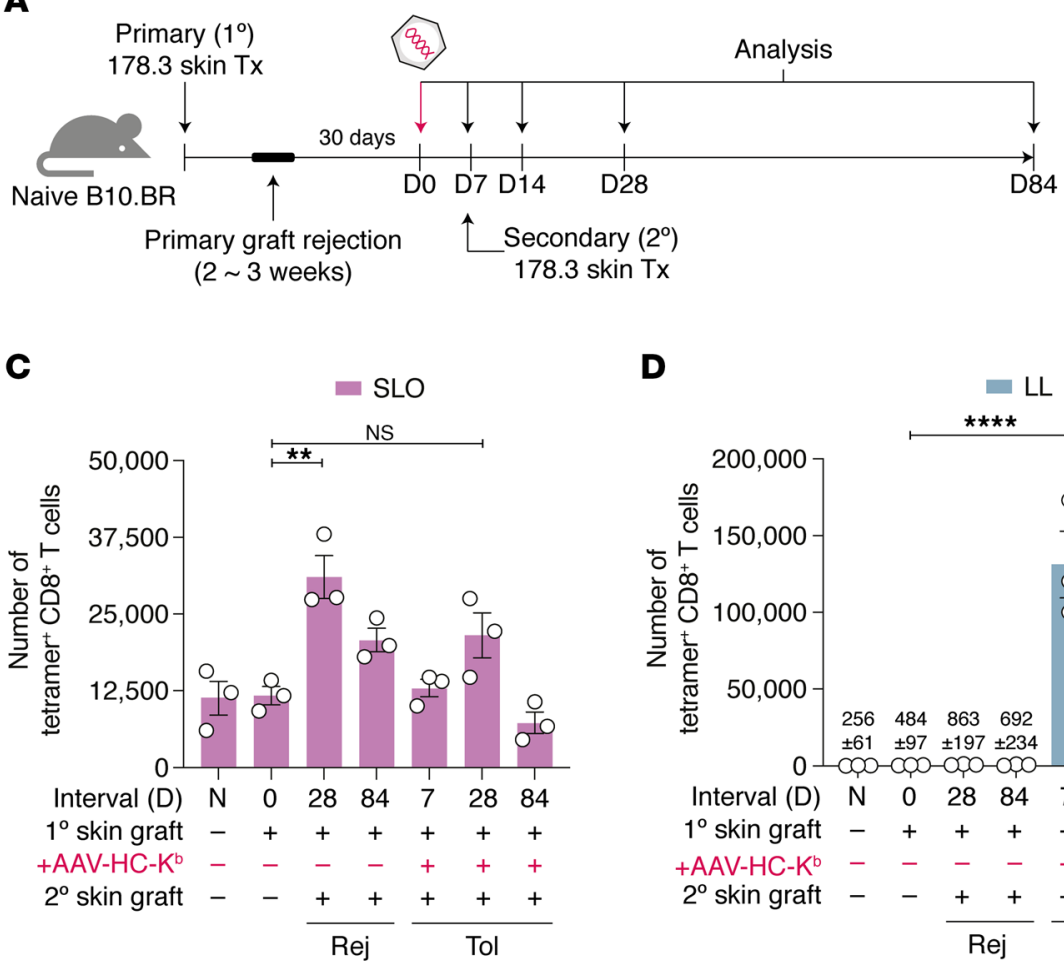

D

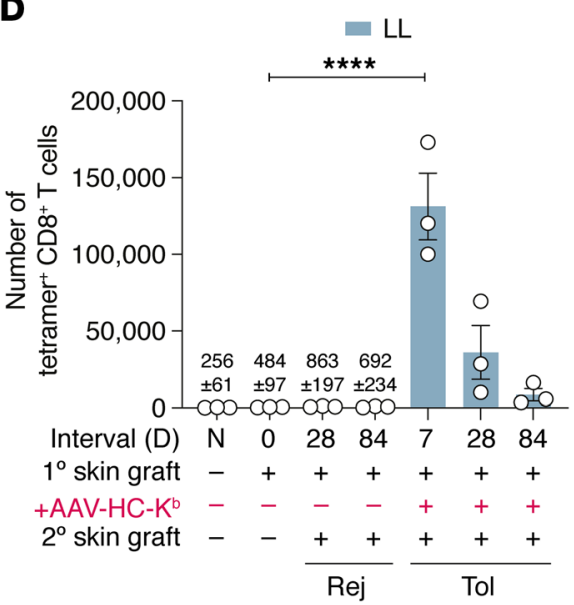

$\mathbf{F}$
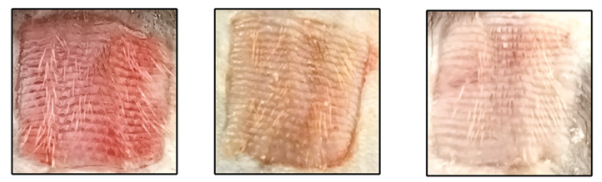

Rejection (D14) Tolerance (D14) Sygneneic

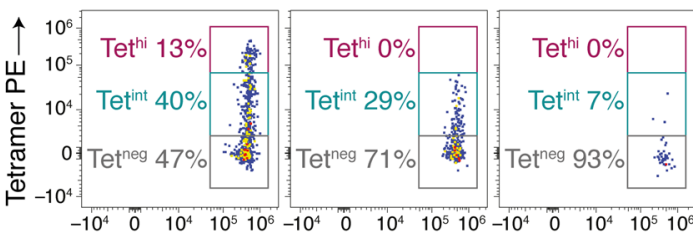
CD90.2 PerCPCy5.5
B
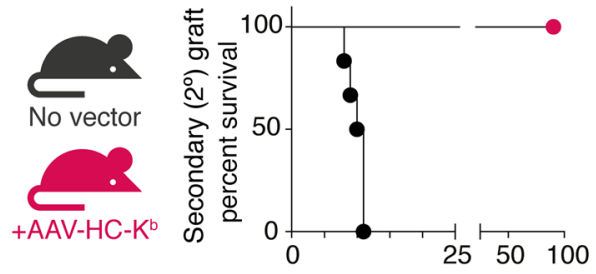

Days after transplant

E

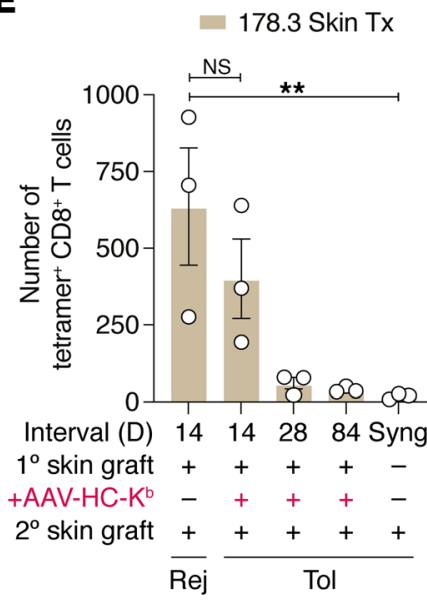

H

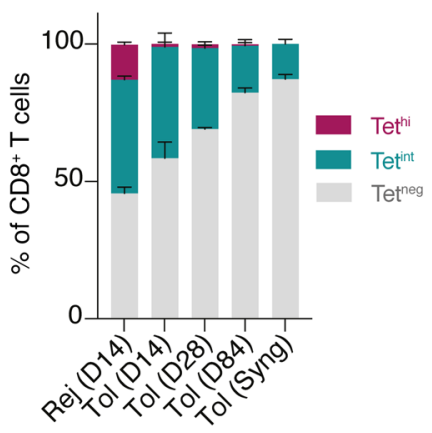

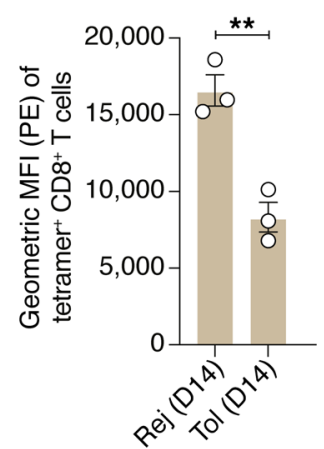

Figure 11. Tracking alloreactive T cells using a tetramer panel. (A) A 5-tetramer panel was used to enumerate and phenotype alloreactive CD8 ${ }^{+} \mathrm{T}$ cells in a model of secondary skin graft tolerance or rejection. (B) Secondary skin grafts to control mice were promptly rejected, while grafts performed 7 days after inoculation of primed recipients with AAV- $\mathrm{K}^{\mathrm{b}}$ survived indefinitely $(n=6)$. (C) The number of tet ${ }^{+}$cells in pooled SLO expanded 3-fold following rejection of a secondary graft $(12,000 \pm 1500$ versus $31,000 \pm 3500$ cells, $P=0.0021)$, but had not increased significantly after graft acceptance (12,000 \pm 1500 against $22,000 \pm 3700, P=0.29)$. (D) Induction of tolerance in primed mice by inoculation with AAV- $K^{b}$ resulted in a sharp increase of tet ${ }^{+}$cells within the liver (from $480 \pm 97$ to $131,000 \pm 22,000$ cells, $P<0.0001$ ), declining subsequently. (E) Numbers of tet ${ }^{+}$cells in rejecting transplants were similar to those in tolerated grafts on d14 (640 \pm 190 versus $400 \pm 130$ cells, $P=0.78$ ), while few tet ${ }^{+}$cells persisted long-term in accepted grafts. (F) Rejecting skin grafts contained a population of $\mathrm{CD} 8^{+} \mathrm{T}$ cells which stained very strongly with the tetramer panel (representative flow plots from $\left.n=3\right)$. $(\mathbf{F}-\mathbf{H})$ This tetramer-bright population was not detected in tolerated grafts. (C, D, E, G, and $\mathbf{H}$ ) Data are shown as mean \pm SEM, $n=3 /$ group. (C-E) One-way ANOVA in conjunction with Sidak's multiple comparison test, (H) Student's $t$ test: ${ }^{* *} P<0.01,{ }^{* * *} P<0.0001$.

$\mu \mathrm{g}$ pcDNA3.1 $1^{+}$plasmid per reaction (Lonza-AMAXA program X-001, Nucleofector 2b). At 24 hours after transfection, transgene expression was evaluated using flow cytometry.

Mice. Information about all mouse strains used in this study can be found in the Supplemental Methods.

AAV vectors. $\mathrm{H}-2 \mathrm{~K}^{\mathrm{b}}$ and $\mathrm{H}-2 \mathrm{~K}^{\mathrm{d}}$ were cloned as previously described (3). SCT constructs consist of a defined peptide sequence, $\beta 2 \mathrm{~m}$, and MHC I HC joined together by flexible linkers (16). A tyrosine to cysteine substitution at $\mathrm{HC}$ position 84 and a cysteine at the second posi- tion of the peptide $-\beta_{2} \mathrm{~m}$ linker form a disulphide trap (17). SCT $\left(\mathrm{H}-2 \mathrm{~K}^{\mathrm{b}}\right)$ constructs with peptide sequences KIITYRNL or SIINFEKL and a SCT $\left(H-2 K^{d}\right)$ construct with peptide sequence SYFPEITHI (termed SCT-K $\mathrm{K}^{\mathrm{b}}-\mathrm{KIIT}, \mathrm{SCT}-\mathrm{K}^{\mathrm{b}}$-SIIN and SCT-Kd-SYFP, respectively) were codon-optimized and synthesized by GeneArt (Thermo Fisher Scientific). A further $\mathrm{H} 2-\mathrm{K}^{\mathrm{d}}$ sequence incorporating the $\mathrm{Y} 84 \mathrm{C}$ and $\mathrm{A} 139 \mathrm{C}$ mutations (termed HC-K $\mathrm{K}^{\mathrm{d}} \mathrm{YCAC}$ ), was codon-optimized and synthesized by GenScript. All synthesized genes were delivered in pcDNA3.1 ${ }^{+}$ plasmids. The full-length native chicken OVA gene inserted in a pcD- 
A

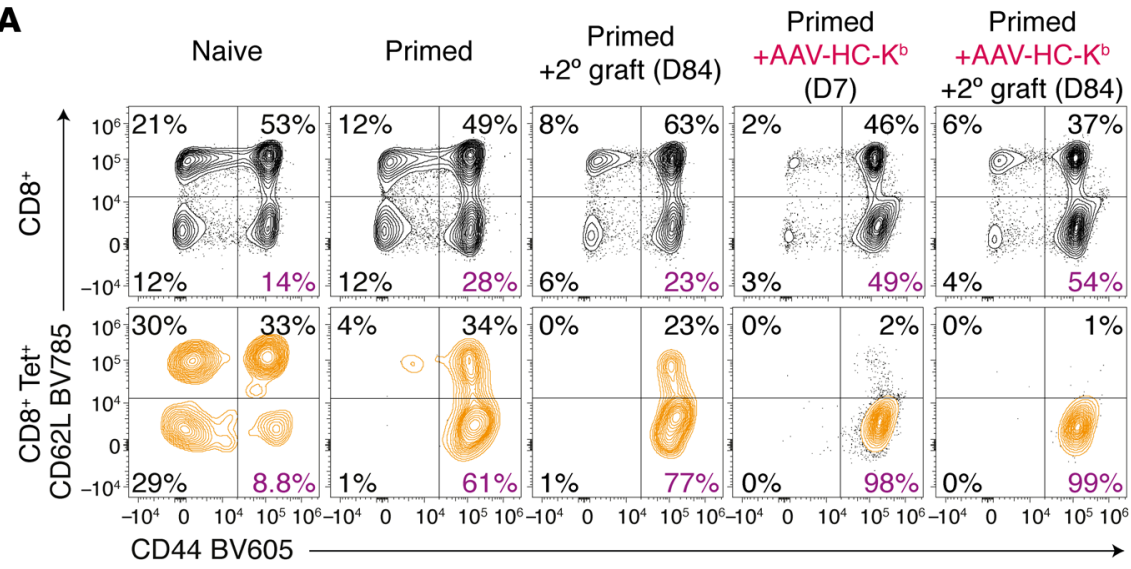

B

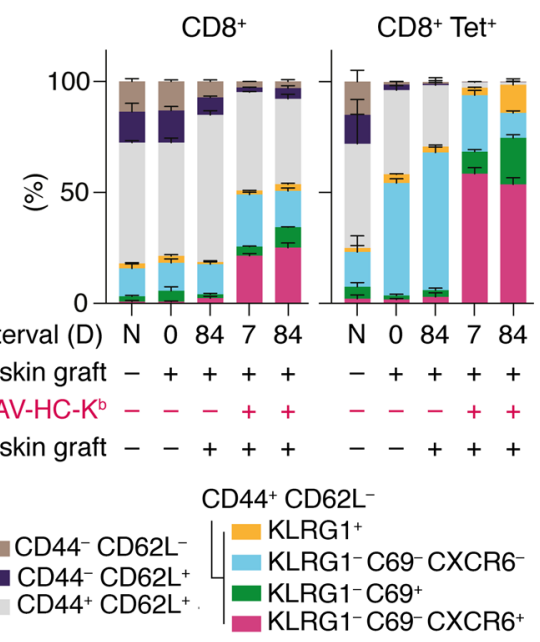

C

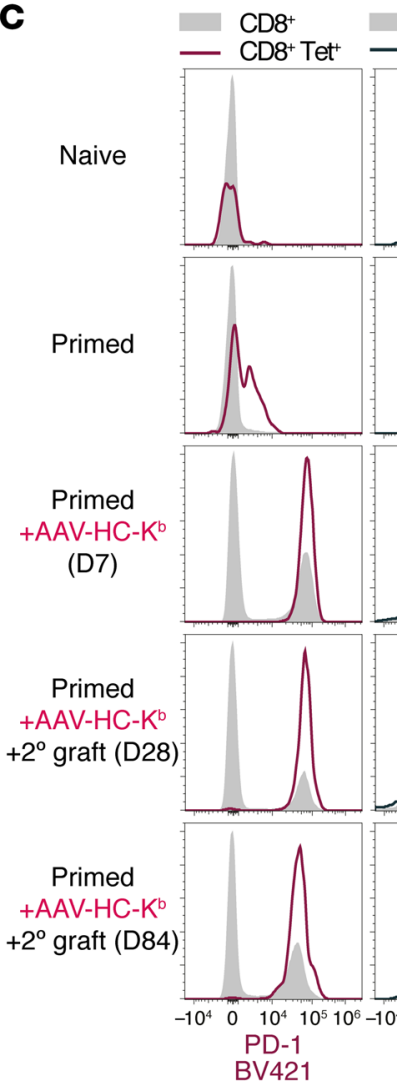

BV42

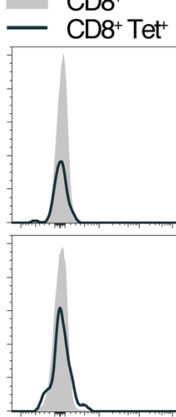

CD8
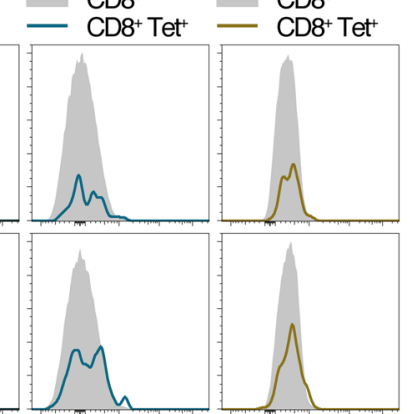

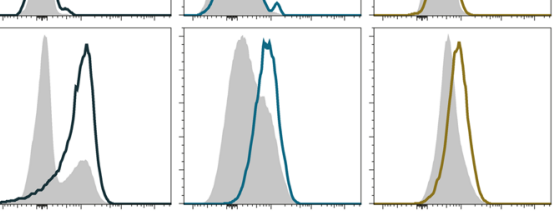

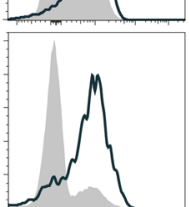
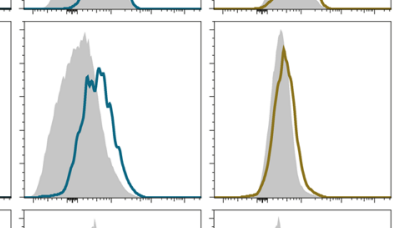

D Rejection (D14) Tolerance (D14)

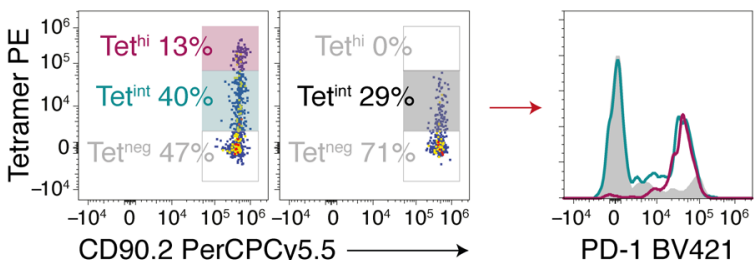

CD90.2 PerCPCy5.5

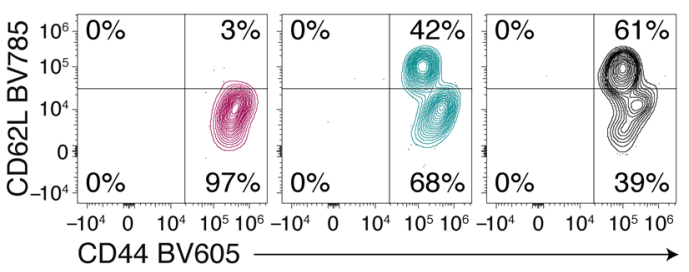

Figure 12. Tetramer-positive alloreactive cells are phenotypically distinct from bulk CD8+ $\mathbf{T}$ cells. Surface markers of naive, effector, and memory status were assessed in bulk and tet ${ }^{+} \mathrm{CD} 8^{+} \mathrm{T}$ cells from naive or transplanted mice. Relatively subtle phenotypic changes in the $\mathrm{CD} 8^{+} \mathrm{T}$ cell population were far more obvious when tet ${ }^{+}$cells were examined. (A) In naive mice, tet ${ }^{+}$liver leukocytes contained all CD8 ${ }^{+} T$ cell subsets, whereas in mice having rejected a primary or secondary graft, tet ${ }^{+}$cells were exclusively antigen-experienced, comprising both central memory and effector/resident memory cells. (B) Following exposure to $\mathrm{H}-2 \mathrm{~K}^{\mathrm{b}}$ in the liver, $\mathrm{CD}_{2} \mathrm{~L}^{+}$tet ${ }^{+}$cells were no longer observed, and the majority of cells expressed markers of liver-homing or residency (CD69 and/or CXCR6). (C) By 7 days after inoculation with AAV-K $K^{b}$, tet ${ }^{+}$cells in the liver have upregulated PD-1, TIGIT, Tim-3, and LAG-3. While strong PD-1 expression persists through d84 after tolerance induction, expression of LAG-3, Tim-3, and to a lesser extent TIGIT in the tet ${ }^{+}$population declines over this time. (D) All tet ${ }^{+}$cells isolated from rejecting or tolerated grafts on protocol d14 were antigen-experienced. Tet ${ }^{\text {hi }}$ cells, only present in rejecting grafts, were uniformly CD62L-negative and PD-1 ${ }^{\text {hi }}$. (A, C, and D) Representative flow plots (from $n=3$ ). (B) Data are shown as mean \pm SEM $(n=3)$.

NA3. $1^{+}$plasmid (clone ID: OGa28271) was purchased from GenScript. Gene inserts from pcDNA3.1 $1^{+}$plasmids were cloned into the pAM2AA backbone incorporating the liver-specific human $\alpha-1$ antitrypsin promoter and human ApoE enhancer flanked by AAV2 inverted terminal repeats. Each gene was then packaged into an AAV2/8 vector, purified, and quantitated as previously described (37). AAV vectors were either produced in-house or by the Vector and Genome Engineering Facility, Children's Medical Research Institute, Westmead, Australia. Vector aliquots were stored at $-80^{\circ} \mathrm{C}$. All vectors were used at a dose of $5 \times$ $10^{11} \mathrm{vgc}$ except SCT-K ${ }^{\mathrm{b}}-\mathrm{KIIT}$, which was used at $2 \times 10^{12} \mathrm{vgc}$. Vectors in 
$500 \mu \mathrm{L}$ sterile PBS were administered by intravenous injection under general anesthesia.

Skin transplantation. Skin transplantation was performed as previously outlined (3) and in the Supplemental Methods. Grafts were deemed rejected when less than $20 \%$ of the viable skin graft remained. B10.BR and B10.BR-RAG mice $\left(\mathrm{H}-2^{\mathrm{k}}\right)$ received $\mathrm{H}-2 \mathrm{~K}^{\mathrm{b}}$ singly mismatched allogeneic skin grafts from 178.3 strain donor mice. C57BL/6, Tap1 $1^{\mathrm{f} / \mathrm{fl}}$ and Tap1KOHep mice $\left(\mathrm{H}-2^{\mathrm{b}}\right)$ received $\mathrm{H}-2 \mathrm{~K}^{\mathrm{d}}$ singly mismatched allogeneic skin grafts from B6.Kd donor mice. BALB/c mice $\left(\mathrm{H}-2^{\mathrm{d}}\right)$ received fully allogeneic skin grafts from $\mathrm{C} 57 \mathrm{BL} / 6$ donor mice. Skin transplant donors and recipients were sex-matched. Isolation of infiltrating cells from skin grafts is described in the Supplemental Methods.

Isolation of hepatocytes and leukocytes from liver, spleen, and draining lymph nodes. These procedures were performed as previously described (3). Hepatocytes for immunoaffinity purification experiments underwent further washing with cold PBS before being stored at $-80^{\circ} \mathrm{C}$.

Adoptive transfers. Lymphocytes from portal and mesenteric lymph nodes were collected and processed as above (3). Cells were resuspended in RPMI 1640 medium containing 10\% FCS, and were labeled with $10 \mu \mathrm{M}$ CFSE dye (Thermo Fisher Scientific, catalog C34570) for 4 minutes at room temperature. The reaction was quenched by adding more RPMI 1640 medium containing 10\% FCS. CFSE-labeled lymphocytes were washed with cold RPMI/FCS10 medium, filtered through $40 \mu \mathrm{m}$ nylon mesh, and resuspended in $500 \mu \mathrm{L}$ cold sterile PBS. CFSE-labeled lymphocytes were administered via intravenous injection under general anesthesia. CFSE-labeling and cell viability were assessed using flow cytometry.

Histology and immunostaining. Immunohistochemical staining and histology were performed as previously described (3), and in the Supplemental Methods. Stained sections were examined by a blinded observer.

Confocal imaging. The livers of freshly sacrificed mice were perfused retrogradely via the IVC (3) with $3 \mathrm{~mL}$ PBS and then $10 \mathrm{~mL} 2 \%$ paraformaldehyde (Sigma-Aldrich, catalog 30525-89-4) in PBS. The gallbladder was removed and the liver was fixed in $2 \%$ paraformaldehyde in PBS for 8 hours. A section of the liver was embedded in 3\% agarose (Fisher Biotec, catalog AGR-LM-50) and $150 \mu \mathrm{m}$ thick sections were cut using a Vibratome 1000 Plus Sectioning System (Harvard Apparatus). Sections were blocked with $4 \%$ bovine serum albumin (Tocris Bioscience, catalog 9048-46-8), 5\% normal goat serum (Invitrogen, catalog 31873) and 0.3\% Triton-X 100 (Sigma-Aldrich, catalog 9002-93-1) in PBS for 20 hours at $4^{\circ} \mathrm{C}$. Sections were stained with primary antibodies for 20 hours at $4^{\circ} \mathrm{C}$, washed, then incubated with secondary antibodies for 20 hours at $4^{\circ} \mathrm{C}$, followed by staining with DAPI (Sigma-Aldrich, catalog 28718-90-3) for 1 hour at $4^{\circ} \mathrm{C}$. Primary and secondary antibodies were diluted in blocking buffer. Washing buffer comprised $0.1 \%$ Triton-X 100 in PBS. Images were acquired using a Leica SP8 confocal microscope at $93 \times$ objective magnification with a numerical aperture of 1.35 . The images were analyzed using Imaris v9.5 (Oxford Instruments).

Flow cytometry. Cells resuspended in cold staining buffer (2\% FCS in PBS) were blocked with mouse Fc Block (BD Biosciences, catalog 553141) for 10 minutes at $4^{\circ} \mathrm{C}$ and stained with a panel of antibodies (Supplemental Table 5). Cells were washed twice with PBS before staining with viability dyes Zombie NIR (BioLegend, catalog 423105) or LIVE/DEAD Fixable Blue (Thermo Fisher Scientific, catalog L23105) for 15 minutes at room temperature. Cells were then washed with staining. Sample data were acquired using Fortessa X-20, LSR-II (both BD Biosciences) or Cytek Aurora 5L (Cytek Biosciences) instruments and analyzed using FlowJo version 10 (Becton Dickinson).

ELISpot. IFN- $\gamma$ ELISpot assays were performed according to the manufacturer's protocol (U-Cytech, catalog CT317-PR5). RMA-S cells either pulsed with peptides or transiently transfected with SCT plasmids were irradiated with a dose of 3000 rad. Responders were either OT-I-RAG or Des-RAG splenocytes. For prestimulation, 1 $\times 10^{6}$ irradiated stimulator cells and $1 \times 10^{6}$ responder splenocytes were suspended in $250 \mu \mathrm{L}$ of RPMI/FCS10 medium with penicillinstreptomycin in each well of a 96-well U-bottom plate (Corning, catalog 3788). They were cultured at $37^{\circ} \mathrm{C}$ with $5 \% \mathrm{CO}_{2}$ for 24 hours and then transferred into an antibody-coated polyvinylidene difluoride (PVDF) plate, serially diluted, and incubated for an additional 16 hours. The plates were then developed, and the spots were counted using an AID iSpot plate reader as previously described (1).

pMHC multimer staining. The pMHC multimer staining method was adapted from that of Dolton et al. (38). Cells were incubated with a protein kinase inhibitor, $50 \mathrm{nM}$ dasatinib, for 30 minutes at $37^{\circ} \mathrm{C}$. PE- or APC-conjugated tetramers or dextramers were centrifuged at $16,000 \mathrm{~g}$ for 1 minute to remove aggregates. The cells were stained with $0.5 \mu \mathrm{g}$ pMHC tetramer or pMHC dextramer at $6.4 \mathrm{nM}$ in $50 \mu \mathrm{L}$ (unless stated otherwise) for 30 minutes on ice or for 1 hour at room temperature. Following pMHC multimer staining, the cells were washed with cold staining buffer twice. Samples were incubated with mouse Fc Block (BD Biosciences, catalog 553141) for 10 minutes at $4^{\circ} \mathrm{C}$ and either or both mouse anti-PE and anti-APC were added at $0.5 \mu \mathrm{g}$ or $100 \mu \mathrm{L}$ depending on the pMHC multimer conjugates used. The cells were washed and incubated with a cocktail of antibodies against surface markers for 30 minutes on ice. Viability staining, acquisition, and analysis were performed as above. Dextramers were purchased from Immudex. QuickSwitch Custom Tetramer Kits (MBL International) were utilized to generate multiple tetramers with selected peptides in order to screen an array of pMHC epitopes. Quantitation of peptide exchange with selected peptides was performed according to the manufacturer's protocol.

Immunoaffinity purification. Two replicate samples were prepared for each tissue or experimental group. MHC complexes were isolated from the supernatant of ultracentrifuged tissue lysates by immunoaffinity purification using solid phase-bound monoclonal antibodies SF1-1.1.10 (anti-H-2K $\mathrm{K}^{\mathrm{d}}$ ), K9-178 (anti-H-2K $\left.\mathrm{K}^{\mathrm{b}}\right), \mathrm{Y} 3$ (anti-H-2K $\left.\mathrm{K}^{\mathrm{b}} / \mathrm{K}^{\mathrm{k}}\right)$, and 28.14.8s (anti-H-2D $\mathrm{D}^{\mathrm{b}}$ ) as previously described $(28,39)$. Further information can be found in the Supplemental Methods.

Mass Spectrometry. Reconstituted peptides were analyzed by LC-MS/MS using an information-dependent acquisition strategy on a Q-Exactive Plus Hybrid Quadrupole Orbitrap (Thermo Fisher Scientific) coupled to a Dionex UltiMate 3000 RSLCnano system (Thermo Fisher Scientific) as previously described (28). Further detail is available in the Supplemental Methods. The mass spectrometry data have been deposited to the ProteomeXchange Consortium via the PRIDE (40) partner repository with accession number PXD022695.

Data dependent analysis (DDA). For peptide identification, the acquired raw files were searched with PEAKS Studio X+ (Bioinformatics Solutions) against the Mus musculus (SwissProt) database. The parent mass error tolerance was set to $10 \mathrm{ppm}$ and the fragment mass 
error tolerance to $0.02 \mathrm{Da}$. Oxidation of methionine (M) was set as variable modifications and a FDR cut-off of $5 \%$ was applied (41).

Data independent analysis (DIA). PEAKS Studio $\mathrm{X}+$ was used to generate a spectral library from all DDA data. DIA raw files were imported to Spectronaut 11 Pulsar (Biognosys). The parent mass error tolerance was set to $10 \mathrm{ppm}$ and the fragment mass error tolerance to $0.02 \mathrm{Da}$. Oxidation of $\mathrm{M}$ was set as variable modifications and a peptide list was exported at $Q$ value $=1 \%$.

Immunopeptidomic analysis. Known contaminants were removed from the analysis. Unique peptides from the DDA (replicate 1) and DIA (replicate 2) data sets were combined to increase the coverage of the tissue immunopeptidomes. For analysis requiring spectral intensity values, only DDA data sets were used. Binding motifs of 8-mer peptides from samples that were immunoaffinity purified with K9-178 antibody ( $\mathrm{H}-2 \mathrm{~K}^{\mathrm{b}}$ group) and 9-mer peptides from samples that had been immunoaffinity purified with SF1-1.1.10 antibody ( $\mathrm{H}-2 \mathrm{~K}^{\mathrm{d}}$ group) were visualized using the GibbsCluster2.0 algorithm (NetMHC4.0; ref. 42). For comparison of unique $\mathrm{H}-2 \mathrm{~K}^{\mathrm{b}}$ peptides between different tissues, 8-mer to 11-mer peptides with a predicted half-maximum inhibitory concentration $\left(\mathrm{IC}_{50}\right.$ ) of binding to $\mathrm{H}-2 \mathrm{~K}^{\mathrm{b}}$ less than $500 \mathrm{nM}$ (NetMHC4.0 database) were selected. For comparison of unique $\mathrm{H}-2 \mathrm{~K}^{\mathrm{d}}$ peptides between tissues, all 9-mer peptides were included. The source proteins associated with the eluted peptides were analyzed using the PANTHER Gene Ontology classification system (43). Function classification analysis and statistical overrepresentation tests were performed (44).

Validation of peptide identification using retrospectively synthesized peptides. We validated the identity of a panel of peptides by comparing chromatographic retention and MS/MS spectra of synthesized peptides (GL Biochem) with those of the corresponding eluted peptides, as previously reported (45) and outlined in the Supplemental Methods.

Statistics. Data are represented as mean \pm SEM unless otherwise stated. Unpaired Student's $t$ tests were performed to calculate statistical differences in a single variable between the means of 2 groups, and 1-way analysis of variance (ANOVA) in conjunction with Sidak's multiple comparison tests were used to calculate statistical differences between the means of 3 or more groups. For analysis of 2 variables, 2-way ANOVA with Sidak's multiple comparison tests were used. Graft survival curves were compared using Mantel Cox log-rank tests. Synthetic and corresponding eluted peptide spectra were compared using Pearson correlation tests. The relationship between overall peptide abundance and alloreactive $\mathrm{T}$ cell binding, and the impact of differences in sexes and strains on alloreactive $\mathrm{T}$ cell binding, were analyzed using linear regression and Pearson correlation tests. $P$ less than 0.05 was considered significant. Statistical tests were performed using GraphPad Prism version 8.01 (GraphPad Software). Heatmaps were generated using Morpheus software (https://software. broadinstitute.org/morpheus).

Study approval. All animal procedures were approved by the University of Sydney Animal Ethics Committee (protocol 2017/1253) and carried out in accordance with the Australian code for the care and use of animals for scientific purposes.

\section{Author contributions}

ETS, PB, DGB, AWP, NAM, and AFS designed experiments. ETS, $\mathrm{PF}, \mathrm{MPH}, \mathrm{MLL}, \mathrm{KE}, \mathrm{SHR}, \mathrm{AB}, \mathrm{NLD}$, and NAM performed experiments. IEA, LL, PB, and AWP provided reagents and/or samples. ETS, PF, SHR, AWP, NAM, and AFS analyzed data. ETS, PF, SHR, NAM, and AFS wrote the manuscript. All authors read and approved the manuscript.

\section{Acknowledgments}

The authors thank Nathan P. Croft (Monash University) for discussions of RMA-S peptide-pulsing experiments, and Rochelle Ayala and Iresha Hanchapola (Monash University) for technical assistance. The authors acknowledge the provision of instrumentation and technical support by the Monash Biomedical Proteomics Facility, and by Sydney Cytometry. Computational resources were supported by the R@CMon/Monash Node of the NeCTAR Research Cloud. We thank Laboratory Animal Services, University of Sydney, for superb mouse care, and the Vector and Genome Engineering Facility, CMRI, for AAV vector production and advice. A number of funding bodies provided project and people support. The National Health and Medical Research Council of Australia (NHMRC) provided funding through the Principal Research Fellowship (1137739 to AWP), the Ideas grant APP1183806 (to AFS and NAM), project grants APP1108311, APP1156431, and APP1161583 (to LL), and grants APP1086451 and APP1146677 (to PB and DGB). ML and KE received Research Training Program Postgraduate Awards from the Department of Education and Training, Australian Federal Government. MPH received an Earl Owen Fellowship from the Sydney Medical School Foundation. ETS was supported by the Royal Prince Alfred Hospital Transplant Institute. LL held research grants from the Department of Science and Higher Education of Ministry of National Defense, Republic of Poland, ("Kościuszko" k/10/8047/DNiSW/T-WIHE/3) and the National Science Centre, Republic of Poland (OPUS13) (UMO-2017/25/B/NZ1/02790). PF was granted the Victorian Cancer Agency Fellowship. This project was also supported by grants-in-aid from Sydney Medical School Foundation (to AFS and DGB) and the Myee Codrington Medical Research Foundation (to AFS and ETS).

Address correspondence to: Alexandra F. Sharland, Room 5118, Charles Perkins Centre Hub, New South Wales 2006, Australia. Phone: 61.2.9351.2897; Email: alexandra.sharland@sydney.edu. au. Or to: Nicole A. Mifsud, Room 222, Level 2, 15 Innovation Walk, Monash University Clayton Campus, Victoria 3800, Australia. Phone: 61.3.9902.9311; Email: nicole.mifsud@monash.edu. Or to: Anthony W. Purcell, Room 214, Level 2, 15 Innovation Walk, Monash University Clayton Campus, Victoria 3800, Australia. Phone: 61.3.9902.9265; Email: anthony.purcell@monash.edu.
1. Cunningham EC, et al. Gene therapy for tolerance: high-level expression of donor major histocompatibility complex in the liver overcomes naive and memory alloresponses to skin grafts. Transplantation. 2013;95(1):70-77.
2. Le Guen V, et al. Alloantigen gene transfer to hepatocytes promotes tolerance to pancreatic islet graft by inducing CD8(+) regulatory T cells. J Hepatol. 2017;66(4):765-777.

3. Paul-Heng M, et al. Direct recognition of hepato- cyte-expressed MHC class I alloantigens is required for tolerance induction. JCI Insight. 2018;3(15):e97500.

4. Caron E, et al. The MHC I immunopeptidome conveys to the cell surface an integrative view of 
cellular regulation. Mol Syst Biol. 2011;7:533.

5. Heath WR, et al. Alloreactive T cells discriminate among a diverse set of endogenous peptides. Proc Natl Acad Sci USA. 1991;88(12):5101-5105.

6. Heath WR, Sherman LA. Cell-type-specific recognition of allogeneic cells by alloreactive cytotoxic T cells: a consequence of peptidedependent allorecognition. Eur J Immunol. 1991;21(1):153-159.

7. Aosai F, et al. Different types of allospecific CTL clones identified by their ability to recognize peptide loading-defective target cells. Eur J Immunol. 1991;21(11):2767-2774.

8. Udaka K, et al. A naturally occurring peptide recognized by alloreactive $\mathrm{CD} 8+$ cytotoxic $\mathrm{T}$ lymphocytes in association with a class I MHC protein. Cell. 1992;69(6):989-998.

9. Crumpacker DB, et al. Role of endogenous peptides in murine allogenic cytotoxic $\mathrm{T}$ cell responses assessed using transfectants of the antigen-processing mutant 174xCEM.T2. J Immunol. 1992;148(10):3004-3011.

10. Kuzushima K, et al. The role of self peptides in the allogeneic cross-reactivity of CTLs. J Immunol. 1995;155(2):594-601.

11. Guimezanes A, et al. Identification of endogenous peptides recognized by in vivo or in vitro generated alloreactive cytotoxic T lymphocytes: distinct characteristics correlated with CD8 dependence. Eur JImmunol. 2001;31(2):421-432.

12. D'Orsogna LJ, et al. Endogenous-peptide-dependent alloreactivity: new scientific insights and clinical implications. Tissue Antigens. 2013;81(6):399-407.

13. Mullbacher A, et al. Alloreactive cytotoxic T cells recognize MHC class I antigen without peptide specificity. J Immunol. 1991;147(6):1765-1772.

14. Jankovic $\mathrm{V}$, et al. $\mathrm{T}$ cell recognition of an engineered MHC class I molecule: implications for peptide-independent alloreactivity. JImmunol. 2002;169(4):1887-1892.

15. Smith PA, et al. Peptide-independent recognition by alloreactive cytotoxic T lymphocytes (CTL). J Exp Med.1997;185(6):1023-1033.

16. Yu YY, et al. Cutting edge: single-chain trimers of MHC class I molecules form stable structures that potently stimulate antigen-specific $\mathrm{T}$ cells and B cells. J Immunol. 2002;168(7):3145-3149.

17. Truscott SM, et al. Disulfide bond engineering to trap peptides in the MHC class I binding groove. JImmunol. 2007;178(10):6280-6289.

18. Hein Z, et al. Peptide-independent stabilization of
MHC class I molecules breaches cellular quality control. JCell Sci. 2014;127(pt 13):2885-2897.

19. Jutte NH, et al. Human heart endothelial-cellrestricted allorecognition. Transplantation. 1996;62(3):403-406.

20. Deckers JG, et al. Tissue-specific characteristics of cytotoxic graft-infiltrating $\mathrm{T}$ cells during renal allograft rejection. Transplantation. 1997;64(1):178-181.

21. Martin-Galiano AJ, Lopez D. Computational characterization of the peptidome in transporter associated with antigen processing (TAP)-deficient cells. PLoS One. 2019;14(1):e0210583.

22. Boulanger DSM, et al. A mechanistic model for predicting cell surface presentation of competing peptides by MHC class I molecules. Front Immunol. 2018;9:1538.

23. Van Kaer L, et al. TAP1 mutant mice are deficient in antigen presentation, surface class I molecules, and CD4-8+ T cells. Cell. 1992;71(7):1205-1214.

24. Saini SK, et al. Empty peptide-receptive MHC class I molecules for efficient detection of antigen-specific T cells. Sci Immunol. 2019;4(37):eaau9039.

25. Scifo C, et al. Selection of T-cell receptors with a recurrent CDR3 $\beta$ peptide-contact motif within the repertoire of alloreactive CD8(+) T cells. Eur J Immunol. 2011;41(8):2414-2423.

26. Siu JHY, et al. T cell allorecognition pathways in solid organ transplantation. Front Immunol. 2018;9:2548.

27. Croft NP, et al. Kinetics of antigen expression and epitope presentation during virus infection. PLoS Pathog. 2013;9(1):e1003129.

28. Croft NP, et al. Most viral peptides displayed by class I MHC on infected cells are immunogenic. Proc Natl Acad Sci USA. 2019;116(8):3112-3117.

29. Ekeruche-Makinde J, et al. Peptide length determines the outcome of TCR/peptide-MHCI engagement. Blood. 2013;121(7):1112-1123.

30. DeVette CI, et al. NetH2pan: a computational tool to guide MHC peptide prediction on murine tumors. Cancer Immunol Res. 2018;6(6):636-644.

31. Krebs P, et al. Rapid functional exhaustion and deletion of CTL following immunization with recombinant adenovirus. JImmunol. 2005;174(8):4559-4566.

32. Miller ML, et al. Distinct graft-specific TCR avidity profiles during acute rejection and tolerance. Cell Rep. 2018;24(8):2112-2126.

33. Bentzen AK, et al. Large-scale detection of antigen-specific T cells using peptide-MHC-I multimers labeled with DNA barcodes. Nat Biotechnol. 2016;34(10):1037-1045.

34. Bentzen AK, et al. T cell receptor fingerprinting enables in-depth characterization of the interactions governing recognition of peptide-MHC complexes [published online November 19, 2018]. Nat Biotechnol. https://doi.org/10.1038/ nbt.4303.

35. Woodham AW, et al. In vivo detection of antigen-specific $\mathrm{CD}^{+} \mathrm{T}$ cells by immunopositron emission tomography. Nat Methods. 2020;17(10):1025-1032.

36. Hess SM, et al. Deletion of naïve T cells recognizing the minor histocompatibility antigen $\mathrm{HY}$ with toxin-coupled peptide-MHC class I tetramers inhibits cognate CTL responses and alters immunodominance. Transpl Immunol. 2013;29(14):138-145.

37. Cunningham SC, et al. Gene delivery to the juvenile mouse liver using AAV2/8 vectors. Mol Ther. 2008;16(6):1081-1088.

38. Dolton $\mathrm{G}$, et al. More tricks with tetramers: a practical guide to staining $\mathrm{T}$ cells with peptide-MHC multimers. Immunology. 2015;146(1):11-22.

39. Dudek NL, et al. Epitope discovery and their use in peptide based vaccines. Curr Pharm Des. 2010;16(28):3149-3157.

40. Perez-Riverol Y, et al. The PRIDE database and related tools and resources in 2019: improving support for quantification data. Nucleic Acids Res. 2019;47(d1):D442-D450.

41. Faridi P, et al. A subset of HLA-I peptides are not genomically templated: evidence for cis- and trans-spliced peptide ligands. Sci Immunol. 2018;3(28):eaar3947.

42. Andreatta M, Nielsen M. Gapped sequence alignment using artificial neural networks: application to the MHC class I system. Bioinformatics. 2016;32(4):511-517.

43. $\mathrm{Mi} \mathrm{H}$, et al. PANTHER version 14: more genomes, a new PANTHER GO-slim and improvements in enrichment analysis tools. Nucleic Acids Res. 2019;47(d1):D419-D426.

44. $\mathrm{Mi} \mathrm{H}$, et al. Protocol Update for large-scale genome and gene function analysis with the PANTHER classification system (v.14.0). Nat Protoc. 2019;14(3):703-721.

45. Falth $\mathrm{M}$, et al. Validation of endogenous peptide identifications using a database of tandem mass spectra. J Proteome Res. 2008;7(7):3049-3053. 